\title{
CHEM2D-OPP: A new linearized gas-phase ozone photochemistry parameterization for high-altitude NWP and climate models
}

\author{
J. P. McCormack ${ }^{1}$, S. D. Eckermann ${ }^{1}$, D. E. Siskind ${ }^{1}$, and T. J. McGee ${ }^{2}$ \\ ${ }^{1}$ E. O. Hulburt Center for Space Research, Naval Research Laboratory (NRL), Washington DC, USA \\ ${ }^{2}$ NASA Goddard Space Flight Center (GSFC), Greenbelt, Maryland, USA
}

Received: 6 June 2006 - Published in Atmos. Chem. Phys. Discuss.: 17 July 2006

Revised: 23 October 2006 - Accepted: 25 October 2006 - Published: 30 October 2006

\begin{abstract}
The new CHEM2D-Ozone Photochemistry Parameterization (CHEM2D-OPP) for high-altitude numerical weather prediction (NWP) systems and climate models specifies the net ozone photochemical tendency and its sensitivity to changes in ozone mixing ratio, temperature and overhead ozone column based on calculations from the CHEM2D interactive middle atmospheric photochemical transport model. We evaluate CHEM2D-OPP performance using both short-term (6-day) and long-term (1-year) stratospheric ozone simulations with the prototype high-altitude NOGAPS-ALPHA forecast model. An inter-comparison of NOGAPS-ALPHA 6-day ozone hindcasts for 7 February 2005 with ozone photochemistry parameterizations currently used in operational NWP systems shows that CHEM2D-OPP yields the best overall agreement with both individual Aura Microwave Limb Sounder ozone profile measurements and independent hemispheric $\left(10^{\circ}-90^{\circ} \mathrm{N}\right)$ ozone analysis fields. A 1-year free-running NOGAPS-ALPHA simulation using CHEM2D-OPP produces a realistic seasonal cycle in zonal mean ozone throughout the stratosphere. We find that the combination of a model cold temperature bias at high latitudes in winter and a warm bias in the CHEM2D-OPP temperature climatology can degrade the performance of the linearized ozone photochemistry parameterization over seasonal time scales despite the fact that the parameterized temperature dependence is weak in these regions.
\end{abstract}

\section{Introduction}

In recent years, the world's leading meteorological centers have extended the vertical range of their numerical weather prediction (NWP) and data assimilation (DA) systems from the surface up through the stratosphere $(\sim 10-50 \mathrm{~km}$ altitude)

Correspondence to: J. P. McCormack

(john.mccormack@nrl.navy.mil) and lower mesosphere $(\sim 50-65 \mathrm{~km})$. Some have also added stratospheric ozone $\left(\mathrm{O}_{3}\right)$ as a prognostic trace constituent to their models. Examples include the Integrated Forecast System (IFS) of the European Centre for Medium Range Weather Forecasts (ECMWF) (Untch et al., 1999; Dethof and Holm, 2004), the Global Forecast System (GFS) of the National Centers for Environmental Prediction (NCEP 2003), the Goddard Earth Observing System (GEOS) of NASA's Global Modeling and Assimilation Office (GMAO) (Štajner et al., 2001) and the prototype Navy Operational Global Atmospheric Prediction System-Advanced Level Physics High Altitude (NOGAPS-ALPHA) (Eckermann et al., 2004).

The addition of stratospheric ozone as a prognostic variable is expected to improve overall forecast skill since global NWP systems depend on assimilation of satellite-based temperature measurements to provide accurate initial conditions. These initial conditions are based on inversions of raw radiance measurements that in turn depend on a priori specification of the atmosphere's radiative transmission characteristics. Accurate stratospheric ozone forecasts can therefore lead to improved operational radiance assimilation (Derber and Wu, 1998; John and Buehler, 2004), improved upper tropospheric and lower stratospheric winds through correlations between ozone and dynamics (Peuch et al., 2000), and improved radiative heating rates in NWP models (Jackson and Saunders, 2002).

With the extension of NWP/DA systems into the upper stratosphere, assimilation and advection alone cannot yield accurate ozone forecasts - photochemical effects must also be included. Due to the complexity of ozone photochemistry, it is not currently feasible to implement full ozone photochemistry within a high-resolution operational global NWP system. Instead, photochemical production and loss rates for ozone are often specified using simpler parameterizations based on output from offline zonally averaged twodimensional (2-D) models with complete photochemistry. Until recently, the NASA GEOS and the NCEP GFS ac-

Published by Copernicus GmbH on behalf of the European Geosciences Union. 
counted for ozone photochemistry using production and loss rates from the NASA Goddard Space Flight Center (GSFC) 2-D middle atmosphere model (Fleming et al., 2002). As we will show, this method can produce significant low biases in model ozone compared to observations in the middle and upper stratosphere over a 6-day period. To remove such biases in NASA GEOS analyses (Riishøgaard et al., 2000), the GSFC production rates have been adjusted to force model ozone to relax towards an observed 2-D ozone distribution (Bloom et al., 2005).

Other meteorological centers such as the ECMWF have incorporated a more detailed ozone photochemistry parameterization in their NWP and DA systems (Dethof and Holm, 2004). The ECMWF parameterization is based on the formulation of Cariolle and Dèqué (1986) (hereafter CD86) and specifies not only the net photochemical tendency, but also takes into account the effect of changes in the local mixing ratio, temperature, and overhead ozone column, the latter being a proxy for changes in the incident photolyzing UV irradiance. A preliminary inter-comparison of ozone photochemistry schemes in the NOGAPS-ALPHA model (McCormack et al., 2004) found that the original CD86 scheme (hereafter CD86 V1.0) consistently produced ozone distributions with weaker zonal structure at northern midlatitudes than was observed, a feature also seen in operational ECMWF IFS ozone forecasts. A recent study by Geer et al. (2006a) also identified problems with the column sensitivity term in the CD86 parameterization that affected modeled lower stratospheric ozone values primarily at high southern latitudes in springtime.

Although more detailed evaluations of prognostic ozone in NWP/DA systems are needed, the evidence to date indicates that current methods used to parameterize ozone photochemistry in such systems need improvement. This article introduces a new high-altitude, self-consistent, computationally efficient ozone photochemistry parameterization that corrects some of the problems in existing operational systems that assimilate and forecast ozone using the aforementioned schemes. Section 2 presents a derivation of the photochemistry parameterization and describes how its coefficients are computed using the CHEM2D photochemical transport model. Section 3 describes the NOGAPS-ALPHA NWP model used to test the photochemistry parameterization. Section 4 presents results from several different sets of numerical simulations to demonstrate the performance of the new parameterization in both NWP and climate modeling applications. Section 5 summarizes these results and discusses plans for future development of the photochemistry scheme.

\section{CHEM2D ozone photochemistry}

\subsection{Background}

The distribution of ozone throughout the middle atmosphere $(\sim 10-85 \mathrm{~km})$ is determined by the balance between transport effects and the rates of photochemical production $(P)$ and loss $(L)$. Ozone production occurs through a 3-body reaction involving molecular oxygen $\left(\mathrm{O}_{2}\right)$ and atomic oxygen (O). Ozone loss can occur through photolysis and through a complex set of reactions involving atomic oxygen and oxides of hydrogen $\left(\mathrm{HO}_{\mathrm{x}}\right)$, nitrogen $\left(\mathrm{NO}_{\mathrm{x}}\right)$, chlorine $\left(\mathrm{ClO}_{\mathrm{x}}\right)$, and bromine $\left(\mathrm{BrO}_{\mathrm{x}}\right)$. This set includes reactions with very fast and very slow rates, and there is a rapid cycling between stratospheric ozone and atomic oxygen. These properties make this system difficult to solve simultaneously for both $\mathrm{O}_{3}$ and $\mathrm{O}$. To aid in the numerical solution of this system, it is common to develop solutions in terms of "odd oxygen", $\mathrm{O}_{\mathrm{x}}$ (e.g., Brasseur and Solomon, 1986), whose concentration is defined as the sum of the concentrations of $\mathrm{O}_{3}$ and various forms of $\mathrm{O}$. Similarly, the $\mathrm{NO}_{\mathrm{x}}, \mathrm{ClO}_{\mathrm{x}}$, and $\mathrm{BrO}_{\mathrm{x}}$ radicals can be regarded as short-lived members of larger families of total reactive nitrogen $\left(\mathrm{NO}_{\mathrm{y}}\right)$, chlorine $\left(\mathrm{Cl}_{\mathrm{y}}\right)$, and bromine $\left(\mathrm{Br}_{\mathrm{y}}\right)$.

Throughout the stratosphere, the majority of odd oxygen is in the form of $\mathrm{O}_{3}$. The photochemical relaxation time for odd oxygen, $\tau_{\mathrm{O}_{\mathrm{x}}}$, in the lower stratosphere (below $30 \mathrm{~km}$ ) is weeks to months, which is long compared to typical time scales for horizontal and vertical transport. Thus $\mathrm{O}_{\mathrm{x}}$ (and by extension, $\mathrm{O}_{3}$ ) in the lower stratosphere can be considered a passive tracer in numerical simulations over periods of days to weeks. Above $30 \mathrm{~km}, \tau_{\mathrm{O}_{\mathrm{x}}}$ is on the order of several days or less and thus photochemical processes become progressively more important than transport effects with increasing height.

We define the local photochemical tendency of stratospheric ozone as the difference between the production and loss rates $(P-L)$. In CHEM2D-OPP, $(P-L)$ is derived from the odd-oxygen production and loss rates computed with a photochemical model, then scaled by $(1+\hat{p})^{-1}$, where $\hat{p}$ is the partition ratio between the concentrations $[\mathrm{O}]$ and $\left[\mathrm{O}_{3}\right]$, to convert from an odd-oxygen net rate to an ozone net rate.

We next assume that $(P-L)$ is primarily a function of only three environmental variables: the local ozone mixing ratio, $r$, the local temperature $T$, and the overlying ozone vertical column density, $\Sigma$. The local time rate of change of ozone mixing ratio due to photochemistry is then

$$
\frac{\partial r}{\partial t}=(P-L)[r, T, \Sigma] \text {. }
$$

Implicit in this assumption is the fact that the concentrations of chemical families such as $\mathrm{Cl}_{\mathrm{y}}, \mathrm{NO}_{\mathrm{y}}$, and $\mathrm{Br}_{\mathrm{y}}$ vary slowly enough to be considered constant, and thus their contribution to changes in $(P-L)$ are small compared to the effects of faster local changes in $r, T$, and $\Sigma$ (McLinden et al., 2000). This assumption may not be strictly valid under all conditions, for example, in the vicinity of the terminator 
at high latitudes in winter or due to heterogeneous chemical processing of air in the presence of polar stratospheric clouds. In common with other linearized ozone photochemistry schemes, we will seek to parameterize the latter process using different approaches (see Sect. 5 for details).

Linearization of the ozone photochemical tendency (1) has become a standard method for climate and NWP models, starting with the work of Cariolle and Dèqué (1986) and progressing to the similarly motivated works of McLinden et al. (2000) and McCormack et al. (2004). In those papers, the linearization procedures were simply posited with little discussion of the theoretical basis for the linearization approach. The following discussion describes the origins of this method and its validation in the literature through extensive modeldata comparisons.

The linearization approach to photochemical production and loss of stratospheric ozone goes back (at least) to the pioneering work of Lindzen and Goody (1965), who derived analytical expressions for the linearized photochemical production and loss coefficients based on pure oxygen (Chapman) photochemistry. This type of analysis produces a linearized version of the total time rate of change for ozone of the form

$\frac{d r_{\mathrm{O}_{3}}}{d t}=-A r_{\mathrm{O}_{3}}^{\prime}-B T^{\prime}-C \Sigma^{\prime}$,

where the photochemical coefficients $A, B$ and $C$ are derived analytically. Here $r_{\mathrm{O}_{3}}=\bar{r}_{\mathrm{O}_{3}}+r_{\mathrm{O}_{3}}^{\prime}$ is ozone mixing ratio, the sum of equilibrium and perturbation values, and $T^{\prime}$ and $\Sigma^{\prime}$ are similarly defined perturbations of temperature and ozone column density, respectively. This is the same equation derived by Lindzen and Goody (1965), except that they did not consider photolysis perturbations and thus did not derive the final column perturbation term in (2).

This linearizing analytical approach was generalized further by Blake and Lindzen (1973) to include additional reactions with various nitrogen and hydrogen species, and extended still further by Stolarski and Douglass (1985) by using an even larger subset of reactions that included chlorine compounds. These later studies found that, despite the large departures from pure oxygen chemistry, the linearization approach still produced a final tendency equation identical to the Lindzen-Goody form given in (2) (though again without the column term which these studies also did not consider). However, with each successive extension to include a greater subset of photolysis and reaction rate terms, the analytical expressions for the photochemical coefficients $A$ and $B$ became much more complex.

An immediate advantage of linearized schemes was that they provided a simple physical description of how environmental perturbations can influence stratospheric ozone concentrations. This enabled further investigations into how ozone perturbations fed back on temperature via radiative cooling and on dynamics via transport (e.g., Blake and Lindzen, 1973; Strobel, 1977; Hartmann and Garcia, 1979;
Randel, 1993), leading to a number of theoretical predictions to be tested with newly developed satellite measurements. For example, in upper stratospheric regions, where ozone photochemical time scales are typically much shorter than dynamical time scales, dynamics can be ignored to first order. This is equivalent to setting $d r_{\mathrm{O}_{3}} / d t=0$ in (2). If we then also ignore column perturbations, then from (2) linearized ozone photochemistry predicts the following simplified relationship between perturbations of ozone mixing ratios and temperatures:

$r_{\mathrm{O}_{3}}^{\prime}=-\frac{B}{A} T^{\prime}$

where the photochemical coefficients $B$ and $A$ are locally constant and both positive definite in the stratosphere. A number of observational studies confirmed this predicted linear anti-correlation between ozone and temperature (3) (e.g., Barnett et al., 1975; Douglass et al., 1985; Froidevaux et al., 1989; Smith, 1995). More elaborate observational assessments used (2) to accurately describe the ozone response to planetary wave-induced temperature perturbations with increasing altitude, from dynamically controlled regions in the lower stratosphere to photochemically controlled regions in the upper stratosphere (e.g., Randel, 1990; Salby et al., 1990; Randel and Gille, 1991; Smith, 1995). In all these cases, good overall agreement was found between the theoretical predictions of linearized ozone photochemistry models and the observations, provided the perturbations involved were not too large in magnitude and transport effects were properly accounted for (e.g., Douglass and Rood, 1986).

In light of these results, and given the desire to extend the schemes still further to include the complete set of ozonerelated chemical reactions and their rates, numerical solutions became a more attractive option than increasingly complicated analytical solutions. Starting with the work of Cariolle and Dèqué (1986), a method was developed which simply started with Eq. (2), and then computed linearized photochemical coefficients $A, B$ and $C$ numerically using perturbation experiments with numerical models that contained complete descriptions of radiation and chemistry, as discussed in the next section.

With this understanding, the latest generation of linearized ozone photochemistry schemes (Cariolle and Dèqué, 1986; McLinden et al., 2000; McCormack et al., 2004) can be viewed as extensions of the previously validated linearization approach to ozone photochemistry. Thus, we can approximate the unknown function $(P-L)[r, T, \Sigma]$ in Eq. (1) by defining it about some reference state $r_{o}, T_{o}, \Sigma_{o}$, then expanding it about this reference state using a first-order Taylor series expansion. 


$$
\begin{aligned}
\frac{\partial r(\lambda, \phi, p, t)}{\partial t}=(P-L)_{o} & +\left.\frac{\partial(P-L)}{\partial r}\right|_{o}\left(r-r_{o}\right) \\
& +\left.\frac{\partial(P-L)}{\partial T}\right|_{o}\left(T-T_{o}\right) \\
& +\left.\frac{\partial(P-L)}{\partial \Sigma}\right|_{o}\left(\Sigma-\Sigma_{o}\right)
\end{aligned}
$$

where $\lambda$ represents longitude, $\phi$ represents latitude, and $p$ represents pressure as the model vertical coordinate. The subscript " $O$ " attached to $(P-L)$ and its partial derivatives in (4) refers to their values at the reference state $r_{o}, T_{o}, \Sigma_{o}$, and are all zonally averaged quantities. Note the similarities between (2) and (4).

The reference-state production and loss, $(P-L)_{o}$, and the various partial derivative terms about that state in (4) are computed offline using a photochemical model in which the reference state is either specified (for single-column models) or is the equilibrium state of the model (for two-dimensional models). These coefficients are then stored in tabular form as functions of latitude, pressure, and month, with suitable linear interpolation to the desired location. In practice, the values of $r_{o}(\phi, p, t), T_{o}(\phi, p, t)$, and $\Sigma_{o}(\phi, p, t)$ needed in (4) are specified using climatologies based on different sets of long-term observations. The following section provides details of how the partial derivatives are computed using the CHEM2D middle atmosphere photochemical-transport model.

\subsection{The NRL-CHEM2D model}

The zonally averaged CHEM2D model features a fully interactive treatment of radiative, photochemical, and dynamical processes in the middle atmosphere. As in earlier versions (e.g., Summers et al., 1997; Siskind, 2000; Siskind et al., 2003), the model grid points are spaced every $4.8^{\circ}$ in latitude from pole to pole and every $2.6 \mathrm{~km}$ in the vertical domain. The radiative and photochemical calculations are performed once per day, and the model dynamics are updated every $2 \mathrm{~h}$. The model has 47 vertical levels over the pressure range of $p=1000 \mathrm{hPa}$ to $p=2 \times 10^{-5} \mathrm{hPa}(\sim 122 \mathrm{~km}$ altitude $)$.

The dynamical framework of the model is based on the Transformed Eulerian Mean (TEM) formulation, in which the residual meridional circulation is driven by zonally averaged sources of momentum and thermodynamic forcing (Bacmeister et al., 1998). The momentum sources include a parameterization for sub-grid scale gravity wave drag from both stationary and non-zero phase speed gravity waves, the Eliassen-Palm (EP) flux divergence associated with dissipating or breaking planetary waves, and parameterized vertical mixing of momentum by gravity wave breaking and molecular diffusion in the upper mesosphere (McCormack and Siskind , 2002; Siskind et al., 2003). The thermal forcing consists of the net radiative heating rate, prescribed tropospheric heating representing latent heat released by convective activity that is not explicitly included in the model, atmospheric heating and cooling at the surface derived from NCEP climatological temperature analyses, and eddy diffusion of heat by breaking gravity waves in the mesosphere.

CHEM2D computes the net radiative heating using shortwave (UV and near-IR) heating rates and longwave (IR) cooling rates at and below $20 \mathrm{~km}$ from the CLIRAD scheme (Chou et al., 2001; Chou and Suarez, 2002). The heating rates above $40 \mathrm{~km}$ are computed using the same spectral distribution of UV transmittance as in the model photolysis calculations, thus ensuring a consistent treatment of radiative and photochemical processes in the middle atmosphere. Cooling rates above $40 \mathrm{~km}$ are computed using the interactive $\mathrm{CO}_{2}$ parameterization of Fomichev et al. (1998) that allows for non-local thermodynamic equilibrium processes in the model's upper levels. The results from this scheme are merged with the CLIRAD cooling rates using linearly weighted averaging between 20 and $40 \mathrm{~km}$.

The CHEM2D model photochemistry used to compute the reference state ozone net tendency $(P-L)_{o}$ and its partial derivatives (Eq. 4 ) accounts for a total of 54 chemical species (Siskind, 2000). Model reaction rates have been updated using the 2002 JPL values (Sander et al., 2003). As in previous versions, the model uses diurnally averaged photolysis rates computed by averaging hourly J-values, and diurnally averaged reaction rate coefficients derived from precomputed night-day ratios of relevant species (Turco and Whitten, 1978; Summers et al., 1997). Input solar flux used for the CHEM2D photolysis calculations varies as a function of wavelength from 1200-8000 $\AA$ and includes Lyman$\alpha$ effects and both the Schumann-Runge continuum and Schumann-Runge bands for $\mathrm{O}_{2}$ photolysis.

CHEM2D ozone and temperature fields are used in the radiative heating calculations. The resulting diabatic heating, combined with momentum deposition by planetary scale Rossby waves and gravity waves, drive the model's residual meridional circulation, which then redistributes the model's potential temperature and chemical constituents. The new distributions of temperature and ozone subsequently feed back into the model's radiative heating calculations, ensuring that the model ozone distribution is self-consistent with the model radiative heating and transport.

\subsection{Computation of CHEM2D-OPP photochemical coeffi- cients: the net tendency}

We compute the net odd oxygen tendency as

$(P-L)_{\mathrm{O}_{\mathrm{x}}}=(P-L)_{\mathrm{O}_{3}}+(P-L)_{\mathrm{O}^{1} \mathrm{D}}+(P-L)_{\mathrm{O}^{3} \mathrm{P}}$,

where the odd oxygen family includes $\mathrm{O}_{3}$ and both the excited $\left(\mathrm{O}^{1} \mathrm{D}\right)$ and ground state $\left(\mathrm{O}^{3} \mathrm{P}\right)$ forms of atomic oxygen.

It should be noted that (4) formally describes the ozone tendency in terms of an expansion about a reference state (de- 

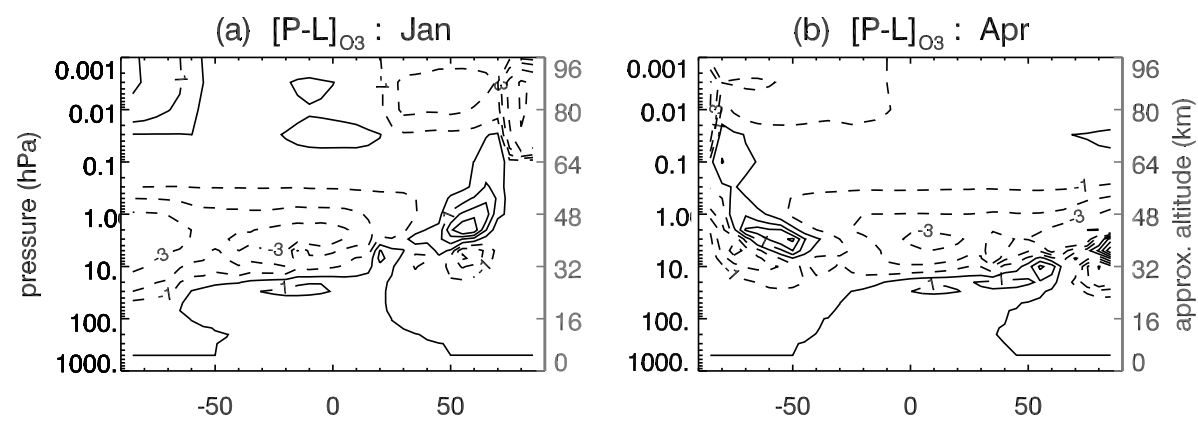

(c) $[\mathrm{P}-\mathrm{L}]_{\mathrm{O} 3}:$ Jul

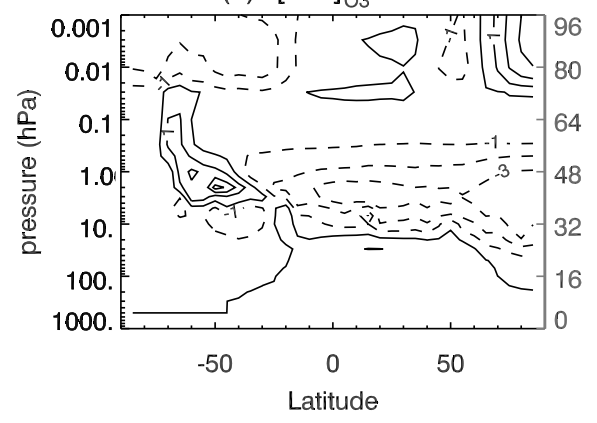

(d) $[\mathrm{P}-\mathrm{L}]_{\mathrm{O} 3}:$ Oct

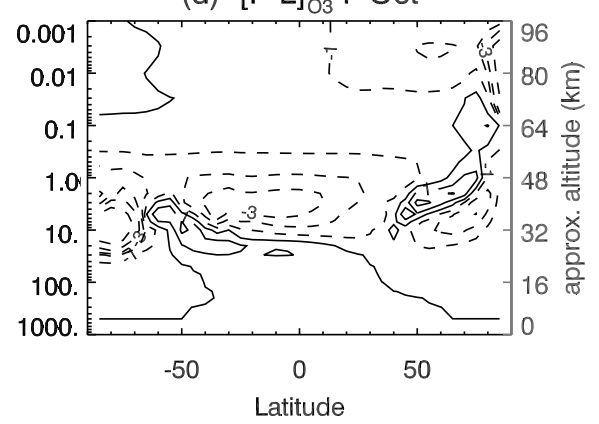

Fig. 1. CHEM2D values of the diurnally averaged net ozone photochemical tendency $(P-L)_{o}$, in ppmv month ${ }^{-1}$, output on (a) 15 January, (b) 15 April, (c) 15 July, and (d) 15 October.

noted with the " $O$ " subscript). For the photochemical coefficients $(P-L)_{o}, \frac{\partial(P-L)_{o}}{\partial r}, \frac{\partial(P-L)_{o}}{\partial T}$, and $\frac{\partial(P-L)_{o}}{\partial \Sigma}$ computed with the CHEM2D model, the reference state is simply the atmospheric state represented by the model at a given latitude, altitude, and time of year. However, when implementing (4) in an NWP or climate model, the perturbation terms $\left(r-r_{o}, T-T_{o}, \Sigma-\Sigma_{o}\right)$ are often computed with respect to a zonal mean climatological reference state $\left(r_{o}, T_{o}, \Sigma_{o}\right)$ derived from observations, which can differ significantly from the photochemical model reference state used to derive the partial derivatives in (4). Such discrepancies can potentially introduce systematic, non-physical biases into the photochemical parameterization.

To illustrate this point, we consider the ozone photochemistry parameterization used in the operational NCEP GFS NWP model (until August 2006) and the NASA GEOS assimilation system, where the local photochemical tendency is expressed simply in terms of the model ozone mixing ratio:

$\frac{\partial r}{\partial t}=(P-L)=P-\tilde{L} r$.

Here $P$ and the ozone loss frequency $\tilde{L}$ are computed with an offline 2-D photochemical model (Fleming et al., 2002).

Normally, $(P-L)$ is a relatively small quantity. However, if the NWP model ozone distribution $r$ differs substantially from the original photochemical model ozone distribution used to derive $P$ and $\tilde{L}$, the production rate $P$ and the loss rate $L=\tilde{L} r$ are not self-consistent. This can lead to an artifi- cial imbalance in the net photochemical tendency $(P-L)$ in (6). In the NCEP GFS, this imbalance produced a substantial negative ozone bias compared to observations in the upper stratosphere (Riishøgaard et al., 2000). To remove this bias from NASA GEOS analyses, the ozone production rates have been adjusted to force the DA system's prognostic ozone to relax back towards an observed 2-D ozone distribution (Bloom et al., 2005). The CHEM2D-OPP parameterization, in contrast, is based upon values of $P$ and $L$ computed from the same model odd oxygen distribution. This ensures the ozone net tendency $(P-L)$ is self-consistent and eliminates the need for any such adjustments of the ozone production rates.

CHEM2D-OPP is intended for use throughout the stratosphere and lower mesosphere. At the higher altitudes of this region, atomic oxygen makes up an increasing share of the odd oxygen mixing ratio. However, since NWP systems and climate models use ozone, and not odd oxygen, as a prognostic variable, the net ozone tendency for CHEM2D-OPP is estimated by scaling CHEM2D values of $(P-L)_{\mathrm{O}_{\mathrm{x}}}$ and its derivatives by the photochemical model partition ratio $\hat{p}=[\mathrm{O}] /\left[\mathrm{O}_{3}\right]$ such that

$(P-L)_{\mathrm{O}_{3}}=(P-L)_{\mathrm{O}_{\mathrm{x}}}(1+\hat{p})^{-1}=(P-L)$.

Hereafter, we will express the CHEM2D-OPP coefficients in terms of this scaled reference state ozone net tendency $(P-L)$ unless otherwise noted.

Figure 1 plots diurnally averaged values of the reference state ozone tendency, $(P-L)_{o}$, from the CHEM2D model 


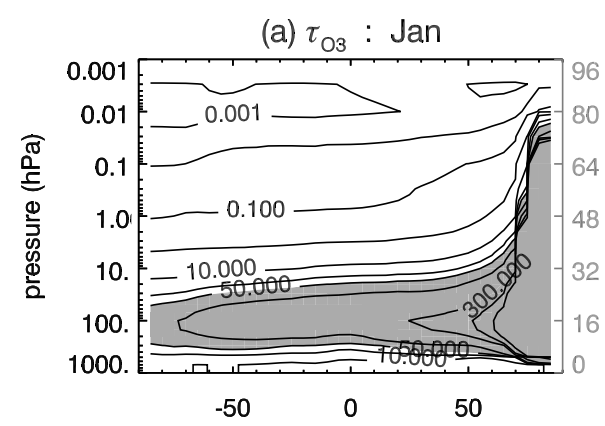

(c) $\tau_{\mathrm{O} 3}:$ Jul

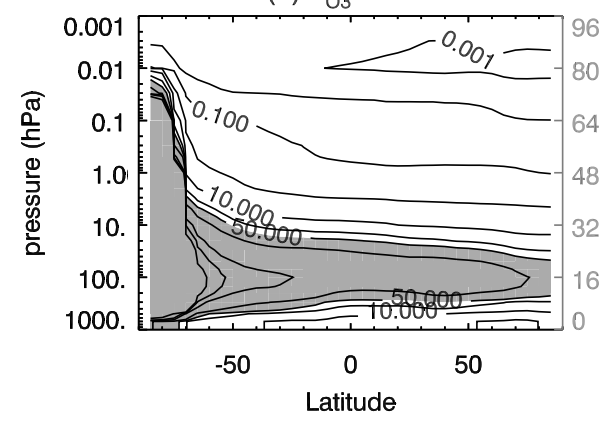

(b) $\tau_{\text {оз }}:$ Apr

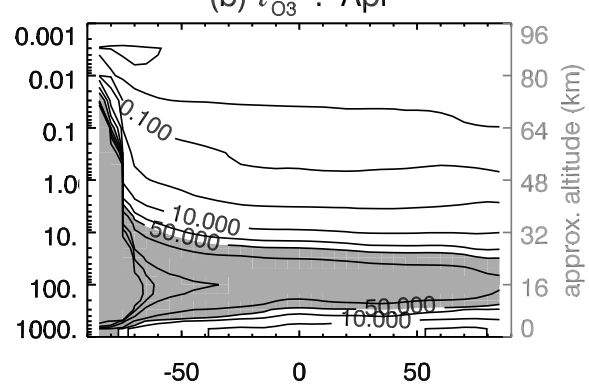

(d) $\tau_{\text {O3 }}:$ Oct

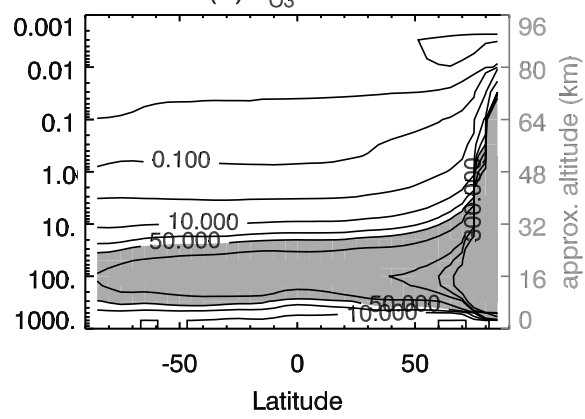

Fig. 2. CHEM2D values of the diurnally averaged ozone photochemical relaxation time $\tau_{\mathrm{O}_{3}}$, in days, output on (a) 15 January, (b) 15 April, (c) 15 July, and (d) 15 October. Contours drawn at 0.001, 0.01, 0.1, 1, 10, 30, 50, 100, 300, 500, and 1000 days. Shading denotes regions where $\tau_{\mathrm{O}_{3}}$ exceeds 100 days.

on 15 January, 15 April, 15 July, and 15 October. The values are on the order of 1-3 ppmv per month, as expected for the reference (equilibrium) state. In the tropical lower stratosphere $(10-100 \mathrm{hPa})$, the net tendency is positive throughout the year. The largest positive tendencies occur in the upper stratosphere $(1-10 \mathrm{hPa})$ near $50^{\circ}-60^{\circ}$ latitude in the winter hemisphere. Large negative tendencies occur throughout much of the year at levels above $0.1 \mathrm{hPa}$, with the exception of summertime polar regions where the net tendency is positive. The altitude, latitude, and seasonal dependences of $(P-L)_{o}$ in Fig. 1 are determined by odd oxygen production, through $\mathrm{O}_{2}$ photolysis, and odd oxygen losses, through reactions involving the $\mathrm{NO}_{\mathrm{x}}, \mathrm{ClO}_{\mathrm{x}}, \mathrm{HO}_{\mathrm{x}}$, and $\mathrm{BrO}_{\mathrm{x}}$ families and long-lived constituents. The spatial and temporal distributions of these long-lived constituents are determined by transport, and so the net tendency reflects the balance between photochemical and dynamical processes. As noted by McCormack et al. (2004), CHEM2D estimates of $(P-L)_{o}$ are in good overall agreement with other photochemistry models (Cariolle and Dèqué, 1986; Fleming et al., 2002).

2.4 Computation of CHEM2D-OPP photochemical coefficients: partial derivatives

To evaluate the coefficient $\left.\frac{\partial(P-L)}{\partial r}\right|_{o}$, we use the fact that this term can be expressed in terms of the ozone photochemical relaxation time $\tau_{\mathrm{O}_{3}}$, i.e.:

$$
\left.\frac{\partial(P-L)}{\partial r}\right|_{o}=-\tau_{\mathrm{O}_{3}}^{-1} .
$$

As shown in the Appendix, the ozone relaxation time $\tau_{\mathrm{O}_{3}}$ is computed from the sum of CHEM2D odd oxygen loss rates $L$ involving reactions with $\mathrm{NO}_{\mathrm{x}}, \mathrm{ClO}_{\mathrm{x}}, \mathrm{HO}_{\mathrm{x}}$, and $\mathrm{BrO}_{\mathrm{x}}$.

Figure 2 plots the latitude and altitude variations of CHEM2D diurnally averaged $\tau_{\mathrm{O}_{3}}$ values for January, April, July, and October. Throughout the entire lower stratosphere (below $\sim 30 \mathrm{~km}$ altitude or $\sim 10 \mathrm{hPa}$ ) and within polar night, $\tau_{\mathrm{O}_{3}}$ exceeds 100 days and so ozone can be considered a passive tracer in these regions (shaded in Fig. 2). Above $\sim 10 \mathrm{hPa}(\sim 30 \mathrm{~km})$ in sunlit regions, $\tau_{\mathrm{O}_{3}}$ becomes progressively shorter compared to transport time scales, and so ozone is controlled mainly through photochemistry. It follows that in the presence of a non-zero difference between the model ozone mixing ratio $r$ and the assumed reference (climatological) ozone mixing ratio $r_{o}$ in the upper stratosphere, the second term on the right hand side of (4) will quickly "relax" $r$ towards the climatological value $r_{o}$. In this way, the relaxation coefficient $\left.\frac{\partial(P-L)}{\partial r}\right|_{o}$ acts as a strong upper boundary constraint on the prognostic ozone variable. This is especially true in tropical regions where model dynamics simulate large-scale ascent in the stratosphere that transports ozone rich air from below. Without the relaxation term, values of the model ozone mixing ratio in these regions 


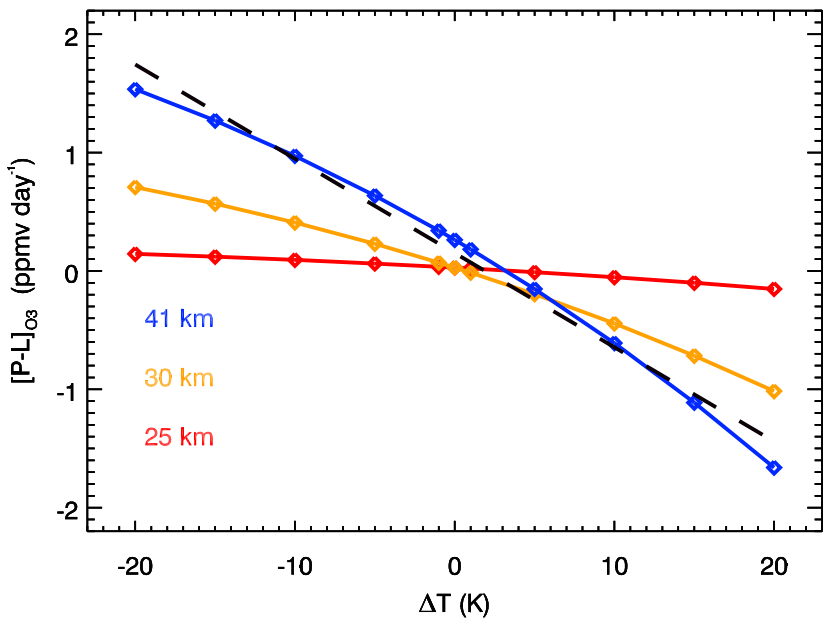

Fig. 3. Temperature dependence of CHEM2D $(P-L)$ for perturbations of $\pm 20 \mathrm{~K}$ under March conditions at the equator. Dashed line indicates least squares fit to the $41 \mathrm{~km}$ (blue) curve.

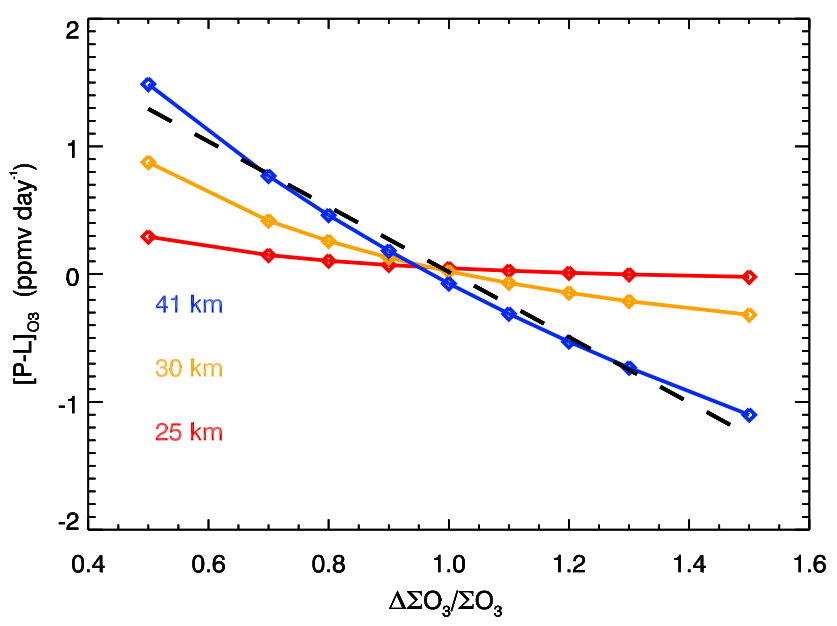

Fig. 4. The $\mathrm{O}_{3}$ column $(\Sigma)$ dependence of CHEM2D $(P-L)$ for perturbations of $\pm 50 \%$ under March conditions at the equator.

of the upper stratosphere would become too large within several days.

To evaluate the temperature and column ozone coefficients, $\left.\frac{\partial(P-L)}{\partial T}\right|_{o}$ and $\left.\frac{\partial(P-L)}{\partial \Sigma}\right|_{o}$, respectively, the CHEM2D model computes $(P-L)$ for a given altitude, latitude, and time of year simultaneously for two sets of reaction rates. Both sets use identical model constituent fields, but one uses a control value of temperature or column ozone, while the other uses a perturbed temperature or column ozone amount. For the coefficient $\left.\frac{\partial(P-L)}{\partial T}\right|_{o}$, a series of these calculations are performed wherein temperature perturbations between \pm 20 $\mathrm{K}$ are introduced to the temperature-dependent odd oxygen reaction rates (see Appendix), and the entire chemical system is then solved with an iterative Newton-Raphson technique until the $(P-L)$ values converge.
Figure 3 plots the differences between the reference state value of $(P-L)$ and the perturbed values as a function of the imposed temperature perturbations at three different altitudes over the equator during January. The slope of the least squares fit to this curve (dashed line) gives the value of the temperature coefficient $\left.\frac{\partial(P-L)}{\partial T}\right|_{o}$.

Similarly, the coefficient $\left.\frac{\partial(P-L)}{\partial \Sigma}\right|_{o}$ is evaluated by introducing ozone column perturbations within the range $\Delta \Sigma= \pm 50 \%$ in the CHEM2D UV transmission functions used to compute the photolysis rate of molecular oxygen and then performing a linear fit to the resulting sensitivity curve. Figure 4 plots the differences between the reference value and perturbed values of $(P-L)$ as a function of the imposed column ozone perturbation at three different altitudes over the equator during March. Figures 3 and 4 show that the dependences of $(P-L)$ on model temperature and overhead ozone column are close to linear over the range of perturbation values likely to be encountered in typical NWP applications (McLinden et al., 2000). Examination of additional sensitivity curves (not shown) confirms this linear behavior throughout the CHEM2D model domain and supports the linearized expansion of $(P-L)$ used by the CHEM2D-OPP scheme in (4).

Figure 5 plots the altitude and latitude dependences of the diurnally averaged temperature coefficient $\left.\frac{\partial(P-L)}{\partial T}\right|_{o}$ throughout the year. Values of $\left.\frac{\partial(P-L)}{\partial T}\right|_{o}$ are negative throughout the sunlit portions of the stratosphere and have the largest magnitudes in the summer hemisphere between $1-10 \mathrm{hPa}$. The negative values of $\left.\frac{\partial(P-L)}{\partial T}\right|_{o}$ between approximately $100-0.2 \mathrm{hPa}$ are qualitatively consistent with the ozone-temperature anti-correlation derived analytically (see Eq. 3) and observed repeatedly in satellite measurements throughout the upper stratosphere. Above $0.2 \mathrm{hPa}(\sim 60 \mathrm{~km}$ altitude), the temperature coefficients change sign and indicate a weak positive ozone-temperature correlation. This change in sign in the mesosphere is qualitatively consistent with the analytically-derived ozone-temperature relationship of Stolarski and Douglass (1985). It is caused by the diminishing temperature dependence of $\mathrm{HO}_{\mathrm{x}}$-related odd oxygen loss with increasing altitude above the stratopause. $\mathrm{HO}_{2}$ is a major source of the odd-hydrogen radicals that dominate odd oxygen loss in the upper stratosphere and mesosphere. In the upper stratosphere, the main sink for $\mathrm{HO}_{2}$ is through reaction with $\mathrm{OH}$ at a rate that is inversely proportional to temperature. In the mesosphere, the sink for $\mathrm{HO}_{2}$ is a series of temperature-independent reactions with hydrogen. In the absence of this temperature dependence in the $\mathrm{HO}_{2}$ sink, the local temperature sensitivity of the odd oxygen mixing ratio to changes in temperature on a constant pressure surface in the mesosphere is instead determined largely by the partition ratio $\hat{p}=\frac{[\mathrm{O}]}{\left[\mathrm{O}_{3}\right]} \propto T^{4.3}$ (see Stolarski and Douglass, 1985, their Appendix A).

Figure 6 shows the altitude and latitude dependences of the diurnally averaged ozone column coefficient $\left.\frac{\partial(P-L)}{\partial \Sigma}\right|_{o}$ 
(a) $d[P-L] / d T:$ Jan

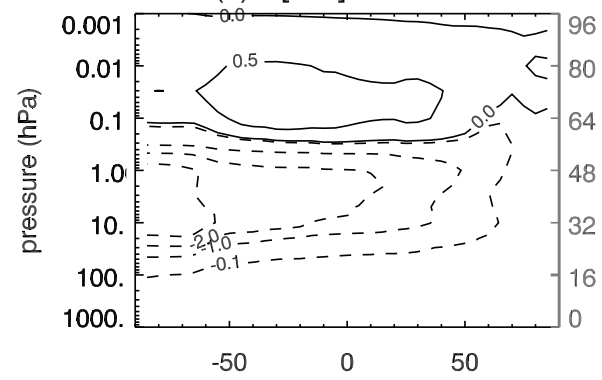

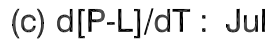

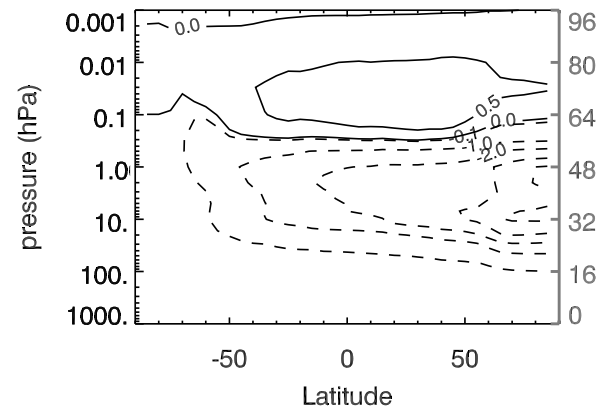

(b) $d[P-L] / d T: A p r$

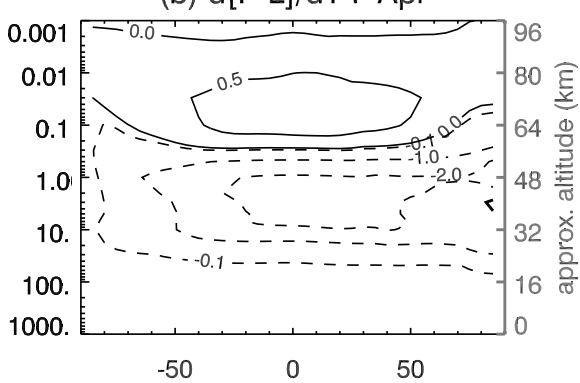

(d) $d[P-L] / d T:$ Oct

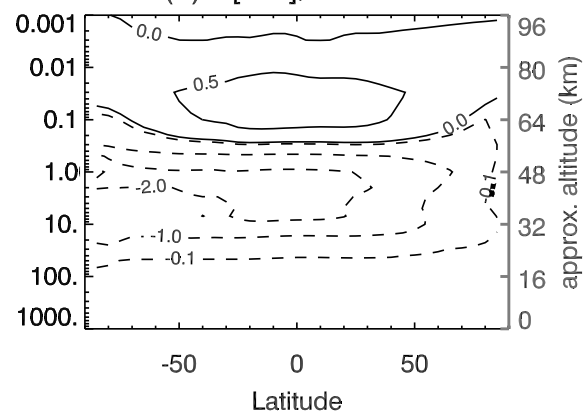

Fig. 5. Altitude-latitude variations of the diurnally averaged CHEM2D-OPP temperature coefficient, $\left.\frac{\partial(P-L)}{\partial T}\right|_{o}\left(\mathrm{ppmv} \mathrm{K}^{-1}\right.$ month $^{-1}$ ) for (a) January, (b) April, (c) July, and (d) October.

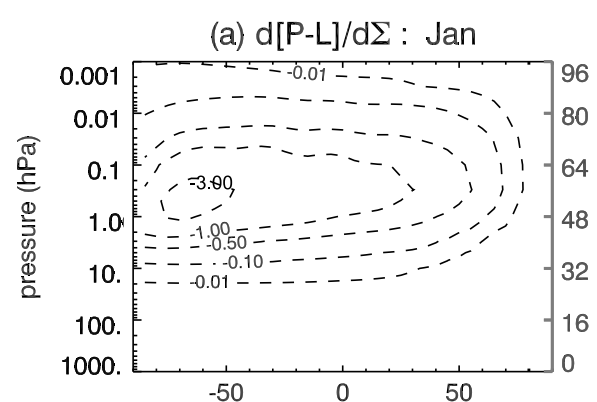

(c) $d[P-L] / d \Sigma:$ Jul

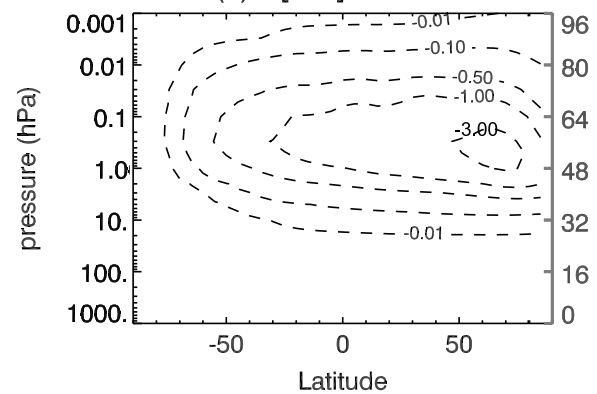

(b) $\mathrm{d}[\mathrm{P}-\mathrm{L}] / \mathrm{d} \Sigma:$ Apr

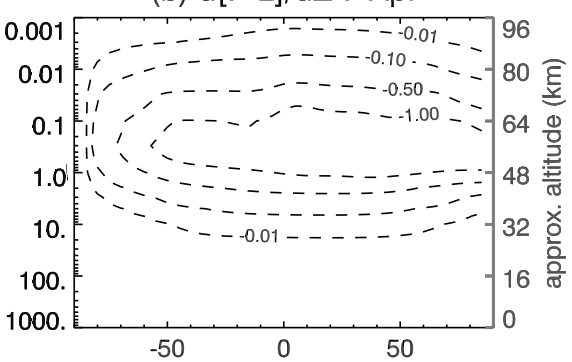

(d) $\mathrm{d}[\mathrm{P}-\mathrm{L}] / \mathrm{d} \Sigma:$ Oct

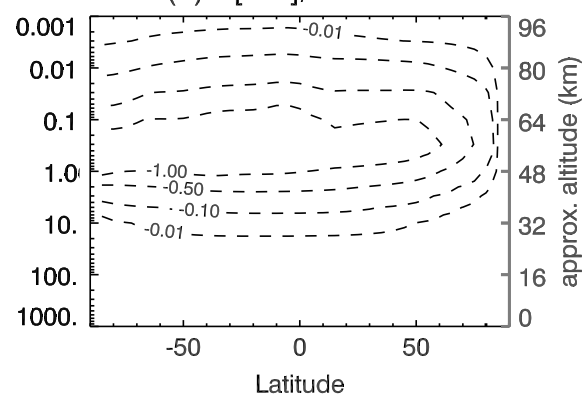

Fig. 6. Altitude-latitude dependences of the diurnally averaged CHEM2D-OPP ozone column coefficient, $\left.\frac{\partial(P-L)}{\partial \Sigma}\right|_{o}\left(\mathrm{ppmv}_{\mathrm{day}}{ }^{-1} \mathrm{DU}^{-1}\right.$ ) for (a) January, (b) April, (c) July, and (d) October. 
throughout the year, expressed in terms of the change in $(P-L)$ per unit change in column $\mathrm{O}_{3}$. Here $\Sigma$ is expressed in Dobson Units (DU=1 mili-atm-cm), which is the equivalent depth per unit area of the vertically-integrated $\mathrm{O}_{3}$ number density normalized to standard temperature and pressure. As with the temperature coefficient, values of the column coefficient have their largest magnitudes in the summer hemisphere.

The column term $\left.\frac{\partial(P-L)}{\partial \Sigma}\right|_{o}$ in (4) approximates the local ozone mixing ratio's sensitivity to changes in the photolysis of molecular oxygen at wavelengths between 200$250 \mathrm{~nm}$, which is a major source of odd oxygen in the stratosphere (see Appendix). It is meant to account for the "selfhealing" feature of stratospheric ozone (e.g., Cariolle and Dèqué, 1986). That is, ozone decreases at higher levels allow more photolyzing UV radiation through to lower levels, where ozone production subsequently increases and offsets the upper level ozone decrease. As a result, $\left.\frac{\partial(P-L)}{\partial \Sigma}\right|_{o}$ coefficients are negative in sign, so that an increase in overlying column ozone produces a local decrease in ozone production.

\section{Prognostic ozone in the NOGAPS-ALPHA model}

The two main components of NOGAPS are a global spectral forecast model (GSFM) and the Naval Research Laboratory Atmospheric Variational Data Assimilation System (NAVDAS). NOGAPS-ALPHA is a prototype high-altitude version of the NOGAPS GSFM (Eckermann et al., 2004). This section offers a brief overview of the NOGAPS-ALPHA GSFM and describes the implementation of the CHEM2DOPP photochemistry scheme.

\subsection{NOGAPS-ALPHA model description}

The prototype 60-level (L60) NOGAPS-ALPHA uses the same hybrid vertical coordinate and top pressure of $0.005 \mathrm{hPa}$ as the L54 version used in McCormack et al. (2004). Additional levels in the L60 version were added near the tropopause to be consistent with the vertical domain of the operational L30 NOGAPS NWP model in this region. The GSFM currently runs with either a T79 or T239 triangular spectral truncation, equivalent to horizontal resolutions of $\sim 1.5^{\circ}$ and $\sim 0.5^{\circ}$, respectively. The model time step $\Delta t$ is $240 \mathrm{~s}$. The radiative heating and cooling rates are applied every time step, but the full radiation calculation is only updated every two hours to reduce the computational burden. Sub-grid scale effects of middle atmosphere gravity waves are parameterized either with Rayleigh friction (McCormack et al., 2004) or with middle atmosphere gravity wave drag schemes available for use in the model (Eckermann et al., 2004).

The stratospheric radiative heating and cooling rate calculations in the operational NOGAPS GSFM utilize zonally averaged monthly mean climatologies of $\mathrm{O}_{3}$ and $\mathrm{H}_{2} \mathrm{O}$ volume mixing ratios. The $\mathrm{O}_{3}$ climatology is based on a combination of ozonesonde and satellite-based measurements (Fortuin and Kelder 1998, hereafter FK98) extending from the surface to $0.3 \mathrm{hPa}$. Above $0.3 \mathrm{hPa}$, the ozone climatology is based on diurnally averaged mixing ratios output from the CHEM2D model. It should be noted that use of diurnally averaged $\mathrm{O}_{3}$ mixing ratios leads to an overestimate of the shortwave heating rates above $0.3 \mathrm{hPa}$ in NOGAPSALPHA, since there is a large diurnal cycle in ozone in this region and radiative heating calculations should only use the lower daytime ozone values (Eckermann and McCormack, 2006). The stratospheric $\mathrm{H}_{2} \mathrm{O}$ climatology combines zonal and monthly mean values from the UARS Halogen Occultation Experiment (HALOE) version 18 data set (Harries et al., 1996) for levels between $100-0.3 \mathrm{hPa}$ and diurnally averaged CHEM2D model output for levels above $0.3 \mathrm{hPa}$. NOGAPSALPHA can use either climatological ozone or the model's prognostic ozone fields to calculate the radiative heating and cooling rates. All results presented here utilize prognostic ozone in the radiative heating and cooling rate calculations.

In this study NOGAPS-ALPHA is run in either "hindcast" mode or "climate" mode. Unlike typical data assimilation runs (Geer et al., 2006a) both modes are free-running simulations in which the atmospheric conditions are not regularly updated from meteorological analyses. Only the specified surface boundary conditions (i.e., sea surface temperatures, sea ice fraction, snow depth, etc.) are updated using either 12-hourly or monthly mean fields for hindcast or climate mode, respectively, which are interpolated to the current model time.

In the hindcast mode used here, NOGAPS-ALPHA is initialized with a so-called "cold-start" procedure using archived operational NOGAPS meteorological analyses and surface boundary conditions for a particular date. This coldstart procedure differs from the way operational NWP models are usually initialized, i.e., with output from a previous forecast run that has been passed through an analysis system to include the latest observations, thus preserving the intrinsic model resolution for all variables. Instead, the cold start procedure combines operational NOGAPS analyses archived on specified pressure levels (i.e., not hybrid model levels), often at slightly degraded horizontal resolution, with zonally averaged climatologies at upper levels where no operational analyses are available. These combined initial fields are then processed with a non-linear normal mode initialization routine to ensure that these fields are in dynamical balance (Eckermann et al., 2004).

Archived NOGAPS analyses prior to June 2003 are based on the Multivariate Optimum Interpolation (MVOI) DA system (Goerrs and Phoebus, 1992) and extend from 1000$10 \mathrm{hPa}$. Since June 2003, the operational analyses have been generated from NAVDAS (Daley and Barker, 2001) and extend from 1013-4 hPa. Archived temperatures, horizontal winds, and geopotential heights from the STRATOI analyses supply initial conditions between $10-0.4 \mathrm{hPa}$ (Goerrs and 
Phoebus, 1992). Above the $0.4 \mathrm{hPa}$ level, initial temperature and horizontal wind fields are extrapolated upwards from the topmost analysis level and progressively relaxed with increasing altitude to monthly zonal mean climatological values. The upper level temperature initialization procedure relaxes to values from the COSPAR International Reference Atmosphere (CIRA86, see Fleming et al., 1990). The upper level horizontal wind initialization procedure relaxes the zonal winds to the URAP climatological values (Swinbank and Ortland, 2003), and relaxes the meridional winds to zero at the model top. For details of the relaxation procedure, see Eckermann et al. (2004).

After this initialization procedure the NOGAPS-ALPHA model is run for 6 days, similar to the operational NOGAPS forecasts. Spin-up of model fields from the cold-start initialization is not an issue between $1000-0.4 \mathrm{hPa}$ where operational analyses are available. Above this level there is some spin-up as model dynamics evolve from their 2-D initial states, but the effect on the ozone hindcasts presented in Sect. 4 is minimal. Most of the results presented in the following section are taken from NOGAPS-ALPHA hindcasts in the 132-h to 138-h time range in order to demonstrate CHEM2D-OPP performance near the limit of the 6-day operational NOGAPS forecast length. In addition, results in Sect. 4 also include examples of hindcast ozone performance over the 12-h to 144-h time range for a particular case on 7 February 2005.

In the climate mode used here, NOGAPS-ALPHA meteorological fields are initialized using the same cold start procedure described above. In both hindcast and climate modes, ozone fields from $1000-0.4 \mathrm{hPa}$ are initialized using NASA GEOS4 ozone analyses (Štajner et al., 2004) for a given date and revert to zonally and diurnally averaged monthly mean ozone values output from the CHEM2D model at altitudes above the $0.4 \mathrm{hPa}$ level. The main difference between hindcast and climate modes is in the specification of boundary conditions. Climate simulations use NCEP/NCAR reanalysis monthly mean sea surface temperature, ice concentration, and snow depth fields averaged over the period 1979-1995 (Kistler et al., 2001).

\subsection{Implementation of CHEM2D-OPP in NOGAPS- ALPHA}

The NOGAPS-ALPHA GSFM transports chemical constituents using the same spectral advection method as for specific humidity and meteorological variables (Hogan and Rosmond, 1991; Eckermann et al., 2004). The model transports both an "active" ozone field, to which the photochemistry parameterization is applied, and a "passive" ozone field, which is not subjected to parameterized ozone photochemistry. All ozone photochemistry parameterizations tested in this study are applied to NOGAPS-ALPHA active ozone fields between 500- $0.1 \mathrm{hPa}$; above this level the active ozone fields are smoothly relaxed to the model 2-D ozone climatology as in
McCormack et al. (2004). Taking the difference between the active and passive ozone fields provides a convenient method to diagnose the performance of the photochemistry parameterizations that we utilize in the present study.

CHEM2D-OPP photochemical tendencies are applied to the NOGAPS-ALPHA prognostic ozone field as in McLinden et al. (2000). Defining the current photochemical steady state ozone mixing ratio $r^{s s}$ as

$$
\begin{array}{r}
r^{s s} \equiv r_{o}+\left[(P-L)_{o}+\left.\frac{\partial(P-L)}{\partial T}\right|_{o}\left(T-T_{o}\right)+\right. \\
\left.\left.\frac{\partial(P-L)}{\partial \Sigma}\right|_{o}\left(\Sigma-\Sigma_{o}\right)\right] \tau_{\mathrm{O}_{3}},
\end{array}
$$

the mixing ratio tendency equation in (4) can be expressed simply as

$$
\frac{\partial r}{\partial t}=-\frac{\left(r-r^{s s}\right)}{\tau_{\mathrm{O}_{3}}} .
$$

However, where McLinden et al. (2000) employ the following analytic solution to (9),

$r(t+\Delta t)=r(t)+\left[r^{s s}-r(t)\right]\left[1-\exp \left(\frac{-\Delta t}{\tau_{\mathrm{O}_{3}}}\right)\right]$,

assuming $\tau_{\mathrm{O}_{3}}$ and $r^{s s}$ remain constant over the model time step $\Delta t$, here we have instead chosen to adopt a standard backward-Euler solution of the form

$r(t+\Delta t)=r(t)+\left[r^{s s}-r(t)\right]\left[\frac{\frac{\Delta t}{\tau_{\mathrm{O}_{3}}}}{1+\frac{\Delta t}{\tau_{\mathrm{O}_{3}}}}\right]$.

The perturbation terms for $\mathrm{O}_{3}$ mixing ratio $\left(r-r_{o}\right)$, temperature $\left(T-T_{o}\right)$, and overlying ozone column $\left(\Sigma-\Sigma_{o}\right)$ in (4) are computed as the differences between 3-D model fields and their respective zonal mean (2-D) climatological values. In the present study, the CHEM2D-OPP formulation employs the same 2- $\mathrm{D} \mathrm{O}_{3}$ mixing ratio climatology described in the previous section (i.e., the combined FK98 and CHEM2D climatology) to specify both $r_{o}$ and $\Sigma_{o}$.

Figure 7 plots these model $\mathrm{O}_{3}$ mixing ratio climatologies for January, April, July, and October. Figure 8 plots the CIRA86 temperature climatology. Figure 9 plots values of $\Sigma_{o}$ computed from the $\mathrm{O}_{3}$ mixing ratio distributions in Fig. 7. For implementation of the CHEM2D-OPP scheme in NOGAPS-ALPHA, the climatological monthly zonal means $r_{o}, T_{o}$, and $\Sigma_{o}$ are interpolated or extrapolated in latitude, pressure, and time to the corresponding model location and day.

The FK98 and CIRA86 climatological data sets were chosen because they were already used to initialize the model at upper levels where meteorological and ozone analyses are unavailable. However, some systematic biases exist in these climatologies. For example, CIRA86 temperatures have a 5-10 K warm bias throughout much of the altitude region between $20-50 \mathrm{~km}$ (Randel et al., 2004). Preliminary tests 
(a) ro (ppmv): Jan

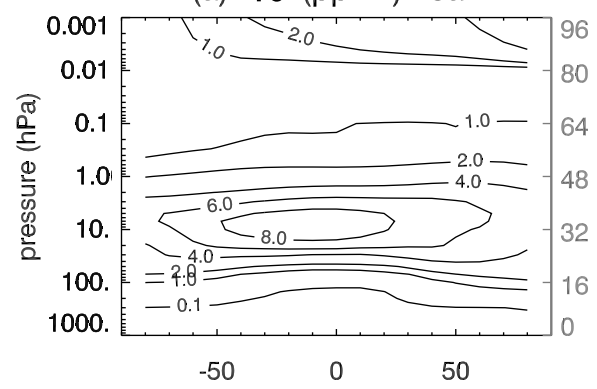

(c) ro (ppmv): Jul

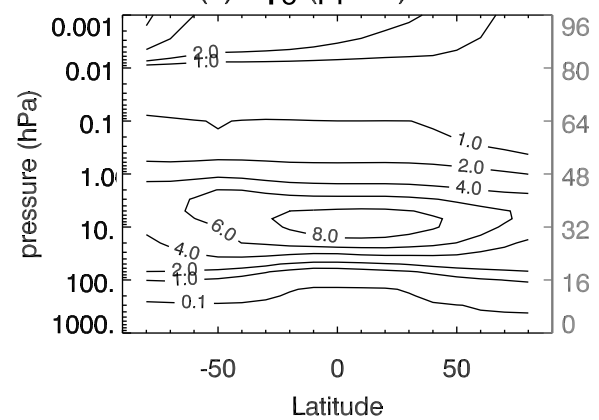

(b) ro (ppmv): Apr

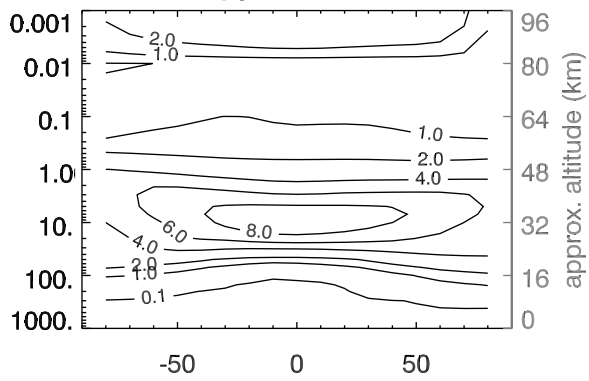

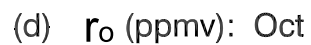

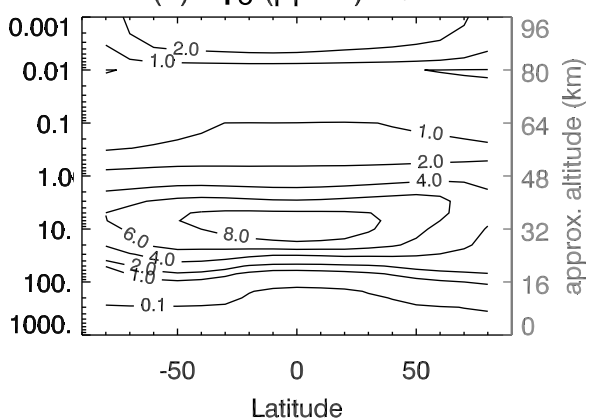

Fig. 7. Monthly zonal mean distributions of $r_{o}$, the climatological $\mathrm{O}_{3}$ volume mixing ratio (ppmv), for (a) January, (b) April, (c) July, (d) October.

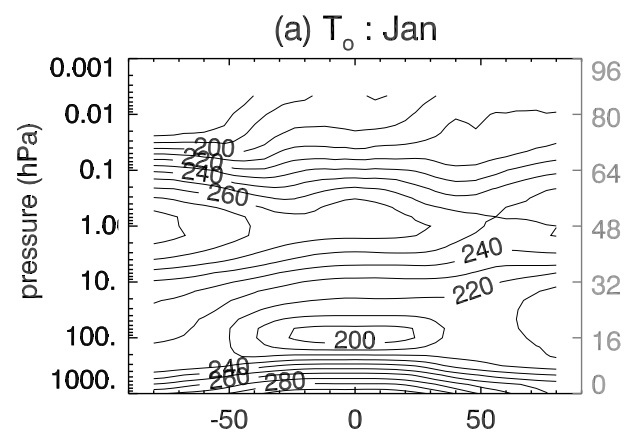

(c) $T_{0}:$ Jul

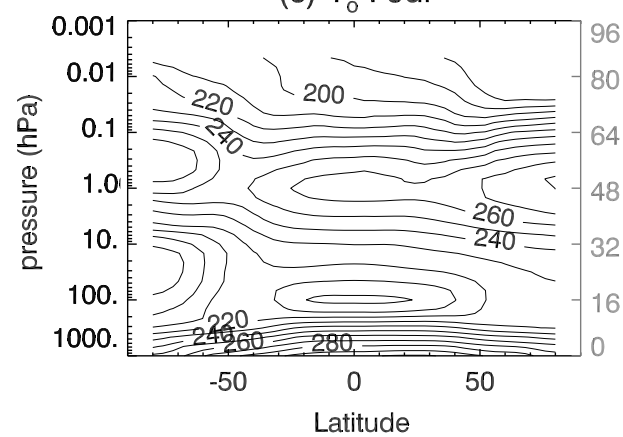

(b) $T_{0}:$ Apr

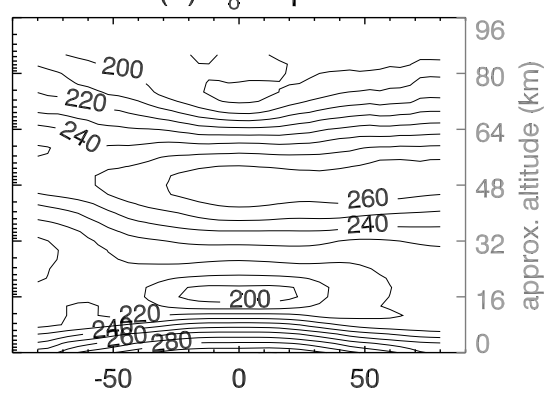

(d) $T_{0}:$ Oct

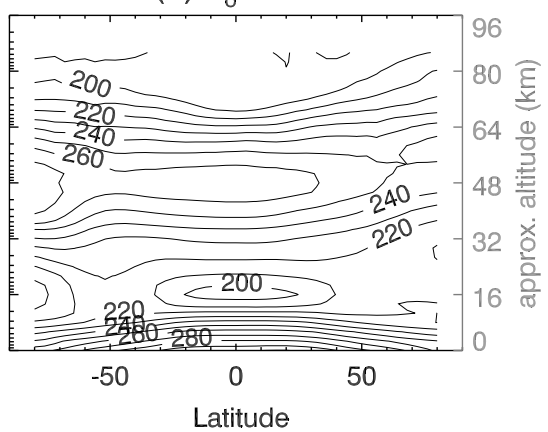

Fig. 8. Monthly zonal mean temperature $T_{o}$ (Kelvin) for (a) January, (b) April, (c) July, (d) October based on the CIRA86 climatology of Fleming et al. (1990). 
(a) $\Sigma_{\mathrm{o}}(\mathrm{DU}): \mathrm{Jan}$

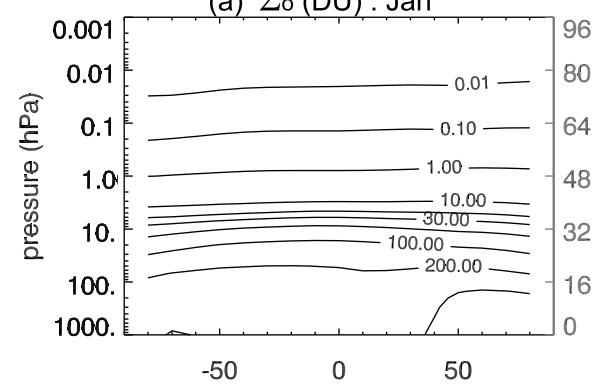

(c) $\Sigma_{\mathrm{o}}(\mathrm{DU}): \mathrm{Jul}$

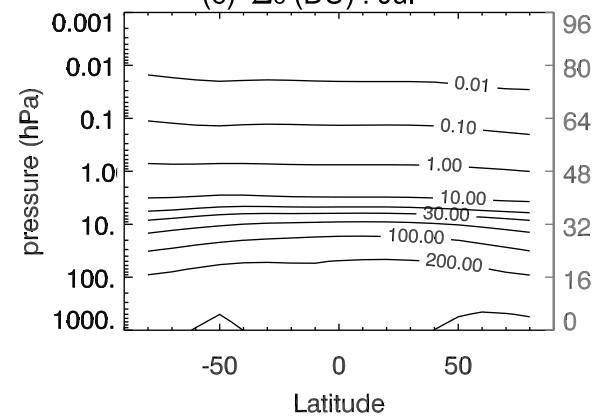

(b) $\Sigma_{\mathrm{o}}(\mathrm{DU}): \mathrm{Apr}$

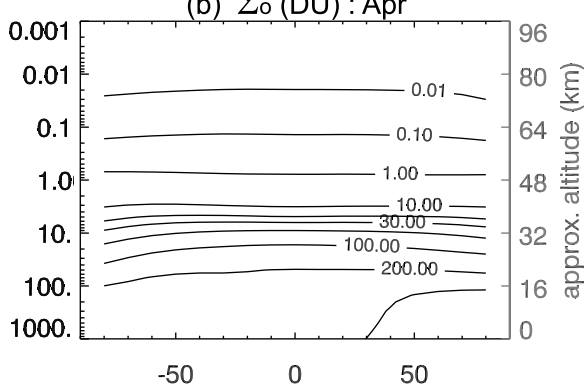

(d) $\Sigma_{0}(\mathrm{DU}):$ Oct

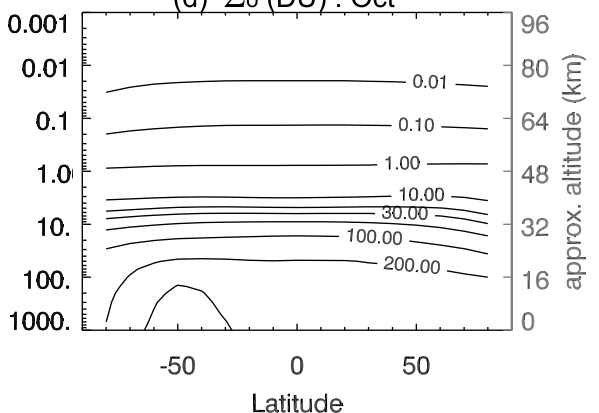

Fig. 9. Monthly zonal mean climatological column ozone abundance $\Sigma_{o}$ (DU) for (a) January, (b) April, (c) July, (d) October.

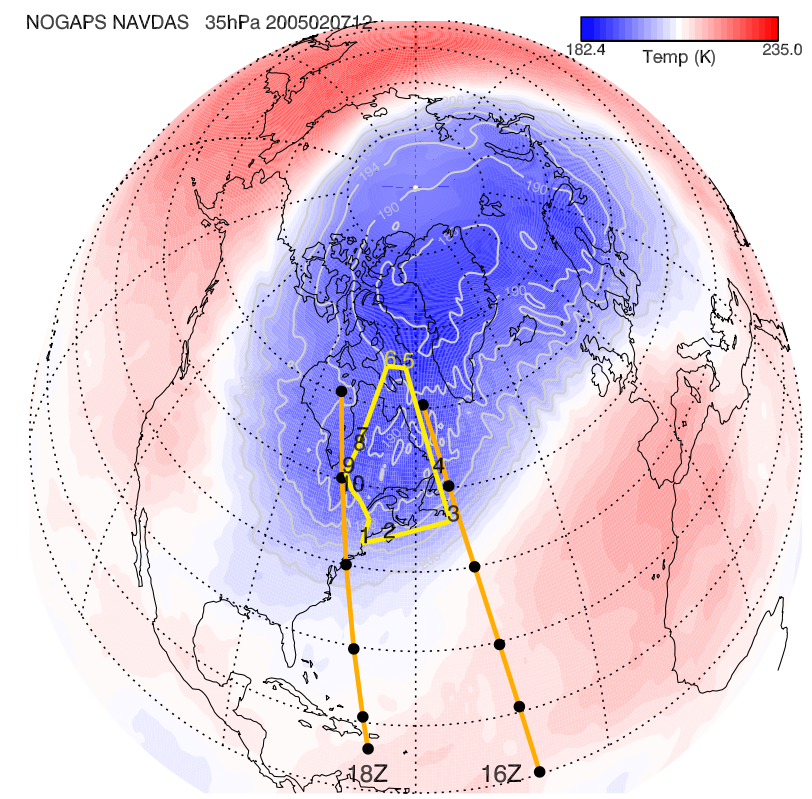

Fig. 10. Map of $35 \mathrm{hPa}$ temperatures from operational NOGAPS (NAVDAS) meteorological analyses at 12:00 UT on 7 February 2005. Superimposed are Aura satellite tracks at 16:00 UT and 18:00 UT (orange lines) with selected MLS ozone profile locations highlighted by filled black circles. The NASA DC8 flight track for this day is plotted in gold with numbers 1-10 denoting individual way points along the flight starting at 14:00 UT and ending at 22:00 UT. 
of CHEM2D-OPP in NWP/DA systems show that the warm bias in the CIRA86 temperatures can produce artifacts in CHEM2D-OPP prognostic ozone fields through the temperature term. A recent study by Geer et al. (2006b) confirms this result and demonstrates that these artifacts are especially pronounced at high latitudes in winter. This issue is discussed further in Sect. 4.2.

In addition, peak ozone mixing ratio values in Fig. 7 for the tropical mid-stratosphere are consistently $1-1.5 \mathrm{ppmv}$ lower than corresponding peak ozone mixing ratios in the extended Version 1.0 URAP climatology (see Wang et al., 1999 and http://code916.gsfc.nasa.gov/Public/Analysis/ UARS/urap/home.html). This is due to the fact that the FK98 stratospheric ozone climatology is based largely on Solar Backscatter Ultraviolet (SBUV) instrument data, which have reduced vertical resolution compared to the more recent ozone profile measurements used to compile the URAP ozone climatology. Future work will compare CHEM2DOPP performance using different zonal mean ozone and temperature climatologies to investigate the sensitivity of the photochemistry parameterization to the choice of reference state conditions.

\section{Results}

\subsection{CHEM2D-OPP in NOGAPS-ALPHA: hindcast mode}

This section presents a case study comparing NOGAPSALPHA ozone hindcasts using CHEM2D-OPP with Aura Microwave Limb Sounder (MLS) measurements of stratospheric ozone and available in-situ profile measurements taken aboard the NASA DC8 flight of 7 February 2005 as part of the Polar Aura Validation Experiment (PAVE). These model-data comparisons are an important means of validating CHEM2D-OPP performance in an NWP model. Additional NOGAPS-ALPHA ozone simulations using the CD86 and GSFC photochemistry parameterizations implemented in the ECMWF and NCEP forecast systems, respectively, are used to assess CHEM2D-OPP performance relative to these existing schemes.

Figure 10 plots $35 \mathrm{hPa}$ temperatures from the operational $1^{\circ} \times 1^{\circ}$ NOGAPS MVOI meteorological analyses for 12:00 UT on 7 February 2005. Superimposed on the temperature map are individual contours showing the location of the coldest temperatures at this level. On this date, the polar vortex was displaced south from the pole, and temperatures below $194 \mathrm{~K}$ extend as far south as $55^{\circ} \mathrm{N}$ over Hudson Bay. Also plotted in Fig. 10 are MLS measurement locations at 16:00 UT and 18:00 UT (orange lines), and the NASA DC8 flight track (shown in gold) of 7 February. The northward leg of the DC8 flight track, along way points 3, 4, and 5 in Fig. 10, matches up with the 16:00 UT MLS flight track. Way points 9 and 10 along the southward leg of the DC8 coincide with the 18:00 UT MLS flight track. As
Fig. 10 shows, the availability of both satellite-based MLS and in-situ DC8 ozone profiles on this date provides an opportunity to evaluate CHEM2D-OPP performance relative to other NWP model photochemistry schemes through a series of model-data comparisons across a wide range of latitudes.

Five different NOGAPS-ALPHA hindcast experiments were conducted, each one initialized at 00:00 UT on 2 February 2005 and run for $144 \mathrm{~h}$. The model initialization and boundary conditions are identical in all five experiments, as described in Sect. 3.1. The only differences are in the individual photochemical coefficients and the climatological reference state distributions of ozone mixing ratio $\left(r_{o}\right)$ and temperature $\left(T_{o}\right)$ used in the photochemistry parameterization that is applied to the model prognostic ozone (see Eq. 4). The first experiment uses the CHEM2D-OPP scheme, the second uses the original CD86 V1.0 coefficients (Cariolle and Dèqué, 1986), the third uses updated values of the CD86 coefficients (denoted as CD86 V2.1, D. Cariolle, personal communication, 2006), the fourth uses the standard GSFC (denoted here as GSFC1) ozone production and loss rates (i.e., no temperature or column dependences), and the fifth experiment uses the adjusted GSFC production rates (GSFC2) as discussed in Sect. 2.3 (Bloom et al., 2005).

Figure 11a plots the zonally averaged 144-h NOGAPSALPHA ozone mixing ratios from the CHEM2D-OPP ozone experiment. Taking the difference between the NOGAPSALPHA active and passive ozone fields provides information on where the parameterized ozone photochemistry is having the largest effect on the model's prognostic ozone. Figures $11 \mathrm{~b}-\mathrm{f}$ plot the zonally averaged differences between the NOGAPS-ALPHA 144-h active and passive ozone fields for each of the five photochemistry schemes tested here.

The difference between CHEM2D-OPP active ozone and passive ozone (Fig. 11b) is largest over the tropical regions between $10-1 \mathrm{hPa}$, where passive ozone exceeds active ozone by up to $1.5 \mathrm{ppmv}$. This is to be expected since upward motion in the equatorial stratosphere transports ozone rich air from the middle to upper stratosphere. Over the 6day model integration the passive ozone fields in the tropical upper stratosphere will increase due to this upward transport, while the parameterized ozone photochemistry will act to reduce ozone mixing ratios in this region, primarily through the relaxation term $\left.\frac{\partial(P-L)}{\partial r}\right|_{o}$. CHEM2D-OPP active-passive ozone differences of $\sim+0.5 \mathrm{ppmv}$ are also present at high northern latitudes between $0.5-5 \mathrm{hPa}$. Downward transport in this region may produce a decrease in passive ozone that would be offset by photochemical production (see, e.g, Fig. 1). However, one would expect that the impact of the parameterized ozone photochemistry on the model's active ozone field would be small due to the reduced sunlight and longer relaxation time $\tau_{\mathrm{O}_{3}}$ at the high winter latitudes (Fig. 2). As discussed later in Sect. 4.2, systematic differences between model temperature and the specified reference state temperature climatology, $T-T_{o}$, may also contribute to the CHEM2D-OPP active-passive ozone differences at the 
(a)

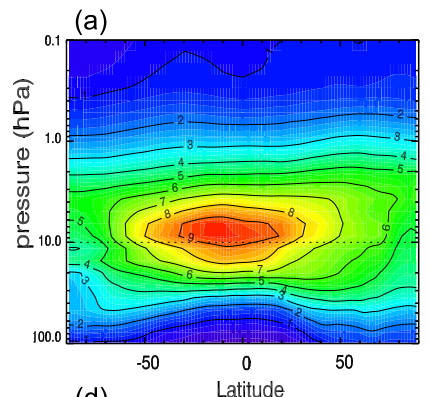

(d)

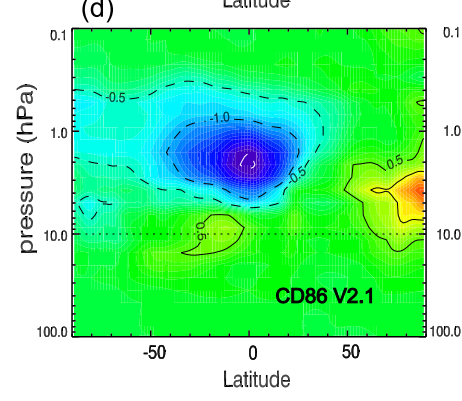

(b)

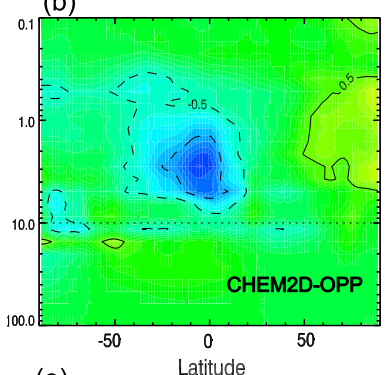

(e)

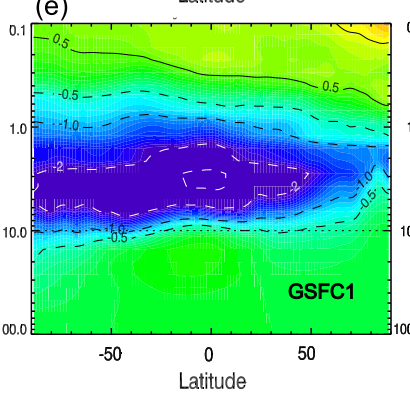

(c)
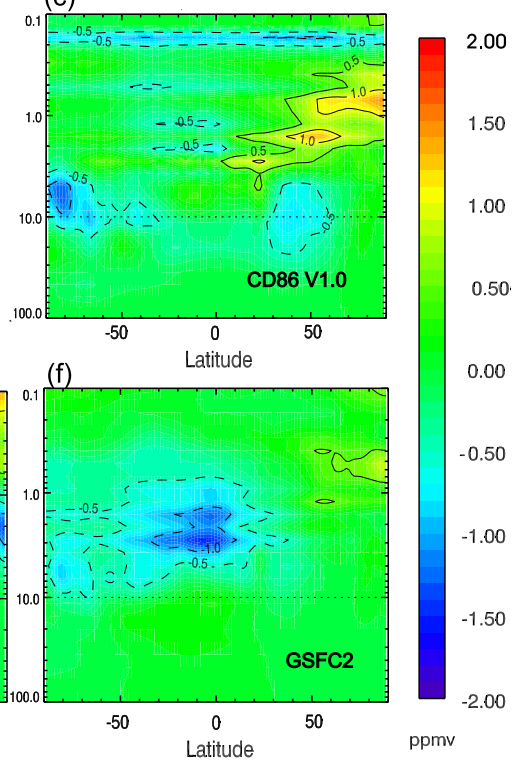

Fig. 11. (a) Zonal mean ozone mixing ratios (ppmv) at hour 144 of a NOGAPS-ALPHA hindcast using CHEM2D-OPP ozone photochemistry initialized at 00:00 UT 2 February 2005. Panels (b) through (f) plot the zonal mean difference between active and passive ozone mixing ratios computed from 144-h hindcast NOGAPS-ALPHA ozone fields using (b) CHEM2D-OPP, (c) CD86 V1.0, (d) CD86 V2.1, (e) GSFC1, and (f) GSFC2 ozone photochemistry parameterizations.
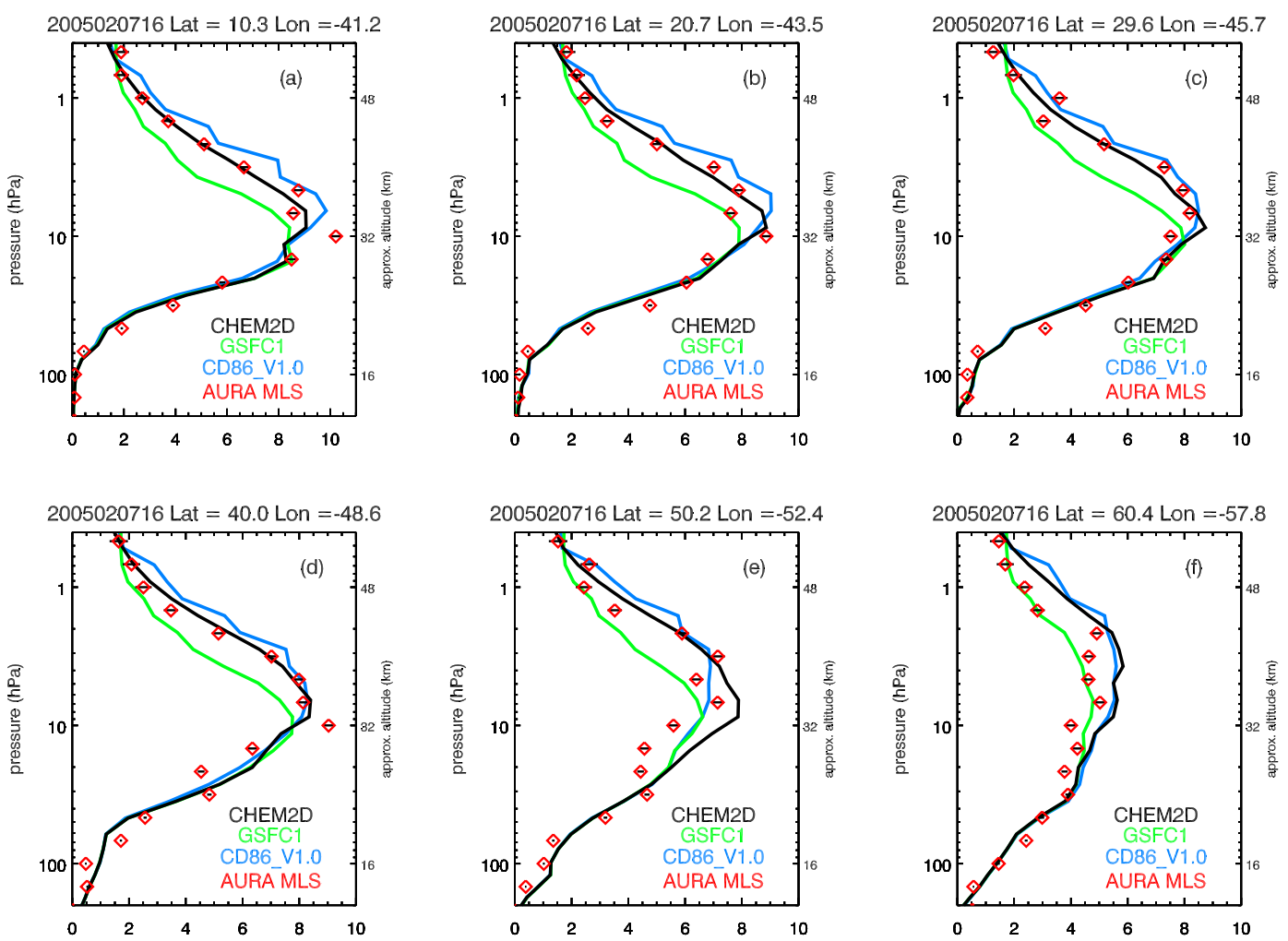

Fig. 12. A comparison of 135-h NOGAPS-ALPHA ozone hindcasts (in ppmv), initialized at 00:00 UT on 2 February 2005 and valid 15:00 UT 7 February using CHEM2D-OPP photochemistry (black curve), CD86 V1.0 photochemistry (blue curve), original GSFC1 photochemistry (green curve), and Aura MLS ozone profile measurements (red diamonds) along the 16:00 UT MLS flight track indicated in Fig. 10. 

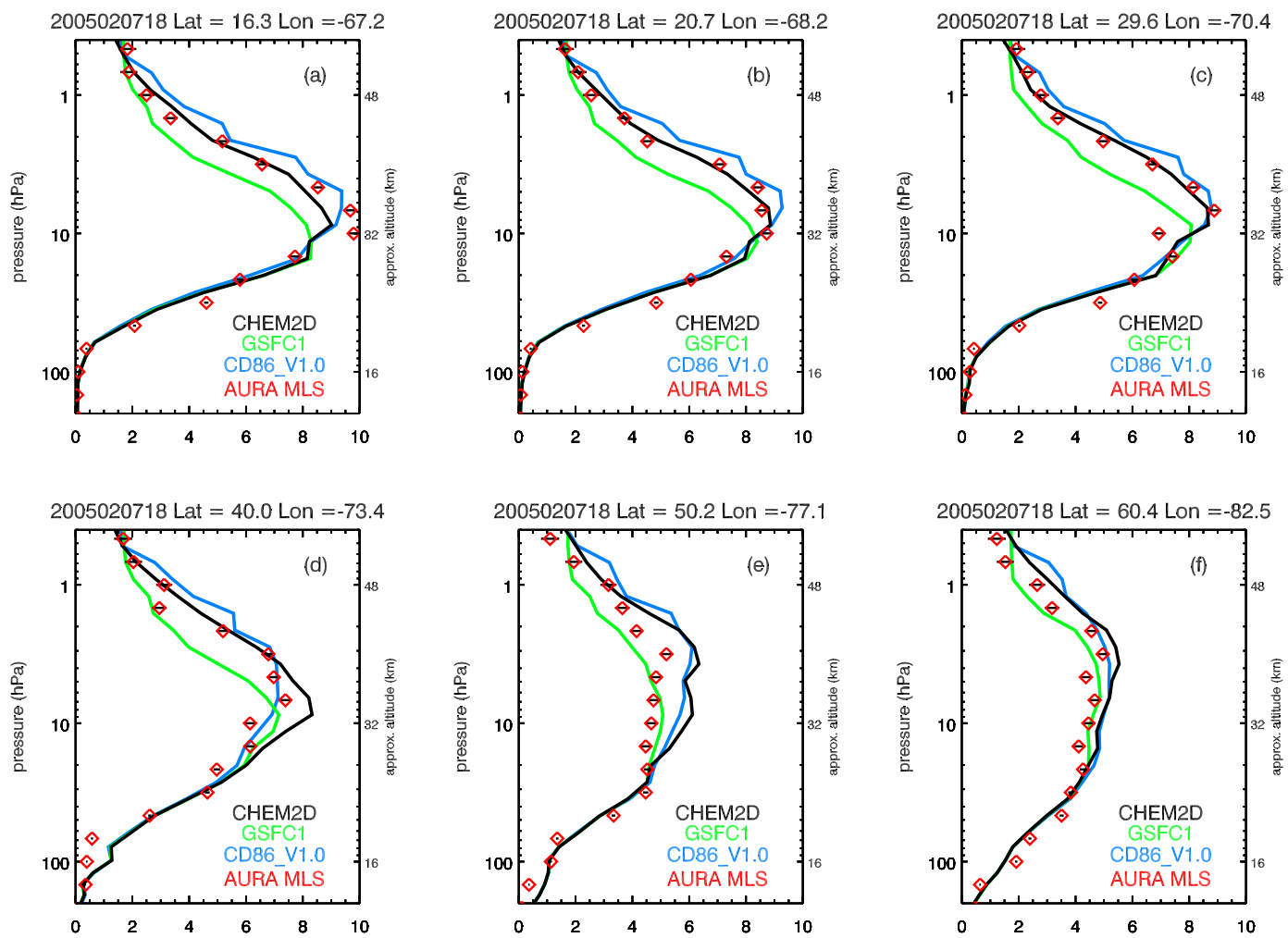

Fig. 13. As in Fig. 12, but plotting NOGAPS-ALPHA ozone profiles from a 138-h hindcast initialized 00:00 UT on 2 February 2007, at locations along the 18:00 UT MLS flight track.

higher northern latitudes in this hindcast experiment.

Active-passive ozone differences from the CD86 V1.0 experiment (Fig. 11c) show negative values of up to $1 \mathrm{ppmv}$ at high southern latitudes near $5-10 \mathrm{hPa}$, and positive values exceeding 1 ppmv at high northern latitudes in the upper stratosphere and mesosphere. Results from the CD86 V2.1 experiment (Fig. 11d) are quite different, showing active-passive differences of -2 ppmv in the tropical upper stratosphere and $+1.5 \mathrm{ppmv}$ at high northern latitudes between $2-10 \mathrm{hPa}$. The CD86 V2.1 active-passive ozone differences are qualitatively similar to the CHEM2D-OPP results in (Fig. 11b), although the large positive differences at the high northern latitudes occur lower down in the stratosphere in the CD86 V2.1 experiment. In the following discussion we present a series of diagnostic calculations showing that the large differences between the CD86 V1.0 and CD86 V2.1 results are due primarily to differences in the column (or "radiation") term $\left.\frac{\partial(P-L)}{\partial \Sigma}\right|_{o}$.

Results from the GSFC1 experiment (Fig. 11e) show very large negative values of the active-passive ozone difference, indicating that the photochemical production and loss rates are removing a large percentage of the ozone between 2$10 \mathrm{hPa}$ over a 6 -day period. These results are consistent with the low ozone biases in the GEOS ozone assimilation experiments reported by Riishøgaard et al. (2000). When the adjusted GSFC2 photochemical rates of Bloom et al. (2005) are used (Fig. 11f), the largest negative active-passive ozone differences in the tropical stratosphere are reduced by a factor of 3 , in better agreement with the CHEM2D-OPP and CD86 $\mathrm{V} 2.1$ results.

Next we compare the active ozone fields output from the five NOGAPS-ALPHA hindcast experiments with Aura MLS ozone profile measurements along the flight tracks marked in Fig. 10. Figures 12 and 13 compare NOGAPSALPHA prognostic ozone simulations using the CHEM2DOPP, CD86 V1.0, and GSFC1 photochemistry parameterizations with MLS observations along the 16:00 UT and 18:00 UT MLS tracks, respectively, on 7 February 2005. Figure 12 plots the six individual Aura MLS profiles indicated on the 16:00 UT path in Fig. 10, with Fig. 12a representing the starting point of this path at $35.5^{\circ} \mathrm{N}$ latitude and Fig. $12 \mathrm{f}$ representing the final point at $60.4^{\circ} \mathrm{N}$ latitude. The MLS ozone profiles represent the standard $240 \mathrm{GHz}$ Version 1.5 Level 2 product (Froideveaux et al., 2006) and range from $215-0.46 \mathrm{hPa}$ with a vertical resolution of $\sim 3 \mathrm{~km}$ in the lower stratosphere. Corresponding precision estimates for each measurement are also plotted in Fig. 12 as black horizontal lines and typically range between $0.2-0.4 \mathrm{ppmv}$ in the stratosphere.

The NOGAPS-ALPHA prognostic ozone profiles in Figs. 12 and 13 represent output at hour 135 (equivalent to $15: 00 \mathrm{UT})$ and hour 138 (18:00 UT), respectively, from 

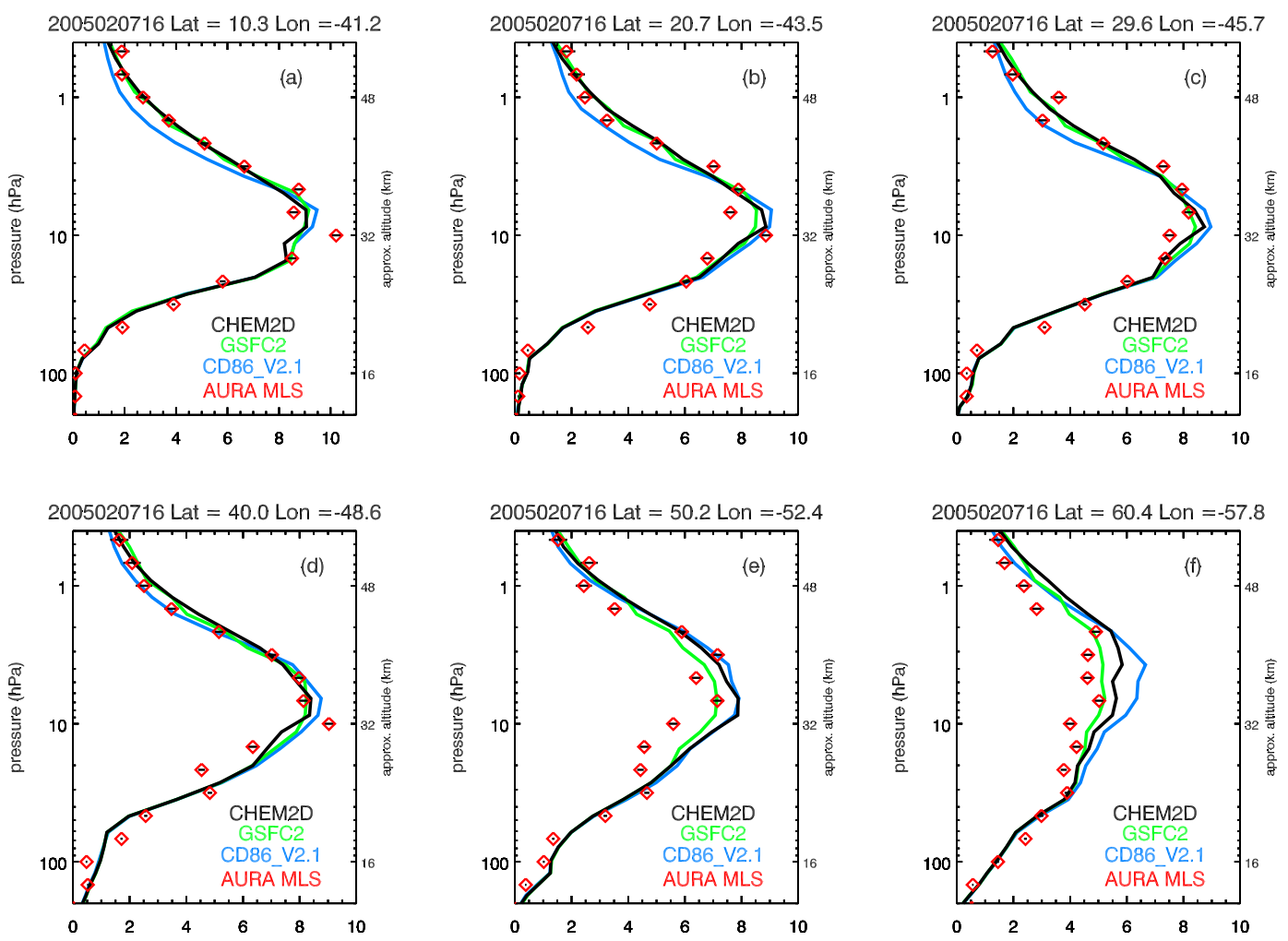

Fig. 14. A comparison of 135-h NOGAPS-ALPHA ozone hindcasts, as in Fig. 12, using CHEM2D-OPP (black curve), the updated CD86 V2.1 photochemistry (blue curve), and the adjusted GSFC2 production rates (green curve).

a T79L60 hindcast simulation initialized at 00:00 UT on 2 February. The T79 spectral truncation produces $\sim 1.5^{\circ}$ spacing in latitude and longitude on the Gaussian model grid. The NOGAPS-ALPHA ozone profiles in Figs. 12 and 13 all lie within $0.75^{\circ}$ latitude/longitude and within $1 \mathrm{~h}$ of the MLS observations.

Comparison of the three 135-h NOGAPS-ALPHA ozone hindcasts (valid 15:00 UT) with the 16:00 UT MLS profiles in Fig. 12 shows that all three modeled ozone profiles agree quite well with each other, and with the MLS data, below the $10 \mathrm{hPa}$ level from $10^{\circ} \mathrm{N}-40^{\circ} \mathrm{N}$ (Fig. $12 \mathrm{a}-\mathrm{d}$ ). At $50^{\circ} \mathrm{N}$ and $60^{\circ} \mathrm{N}$ (Fig. 12e, f), the ozone hindcasts tend to overestimate mixing ratios from $10-30 \mathrm{hPa}$ relative to MLS observations, with CHEM2D-OPP producing the highest mixing ratios. Results from the different photochemistry parameterizations are expected to agree below $10 \mathrm{hPa}$ since transport effects dominate over photochemistry in the lower stratosphere (see Fig. 11). The agreement among the different NOGAPSALPHA hindcasts and the MLS profiles in the lower stratosphere at the lower latitudes indicates that the model dynamics are accurately capturing the large-scale flow in this region. Possible origins of the high-latitude disagreement are discussed below.

Above the $10 \mathrm{hPa}$ level, Fig. 12 shows marked differences between the output from the three photochemistry schemes. The GSFC1 profiles all exhibit excessive loss and grossly underestimate the ozone mixing ratios as compared to the MLS measurements (see Sect. 2.3). The CD86 V1.0 results exhibit an unusual vertical structure above the $10 \mathrm{hPa}$ level, which is most pronounced at the lower latitudes, and leads to overestimates of the ozone mixing ratio at numerous points relative to the MLS profiles. CHEM2D-OPP results above $10 \mathrm{hPa}(\sim 30 \mathrm{~km})$ show good agreement with MLS ozone at the lower latitudes, but tend to overestimate ozone mixing ratios at the higher latitudes (Fig. 12e, f). Similar results are also seen when we compare the 138-h NOGAPS-ALPHA ozone hindcasts with the 18:00 UT MLS profiles (Fig. 13). In this case, however, the CHEM2D-OPP results overestimate the peak in the ozone mixing ratio at $40^{\circ} \mathrm{N}$ (Fig. 13d) as well as at the higher latitudes (Fig. 13e, f).

We now present a second set of comparisons among NOGAPS-ALPHA hindcasts using CHEM2D-OPP photochemistry, the adjusted GSFC2 production rates and the updated CD86 V2.1 scheme. Figures 14 and 15 show that when the $a d-h o c$ adjustments to the GSFC production rates are included, the 135-h and 138-h GSFC2 hindcast ozone profiles show much better agreement with MLS observations. The results with the updated CD86 V2.1 photochemistry no longer show any jagged vertical structure above $10 \mathrm{hPa}$. As we will show later, this is due to a reduction in the size of the ozone column sensitivity term in CD86 V2.1. However, the CD86 V2.1 results do not necessarily represent an overall improve- 

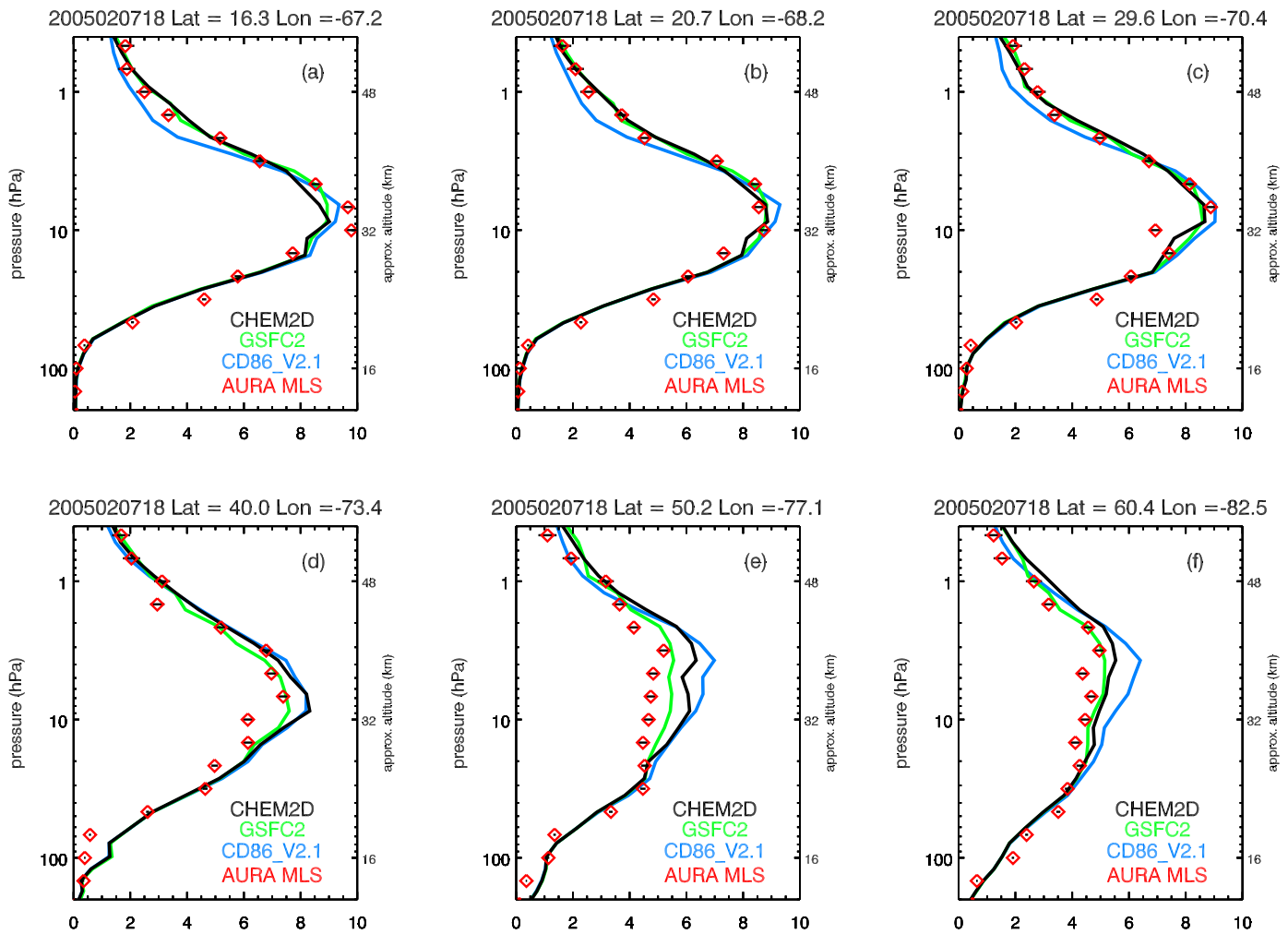

Fig. 15. As in Fig. 14, but plotting NOGAPS-ALPHA ozone profiles 138-h hindcast initialized 00:00 UT on 2 February 2007, at locations along the 18:00 UT MLS flight track.

ment from the CD86 V1.0 results, since they now tend to overestimate ozone mixing ratios at the higher latitudes. For example, Figs. 12e and 14e show that the CD86 V1.0 photochemistry produces better agreement with MLS profiles at $50^{\circ} \mathrm{N}$ and $52^{\circ} \mathrm{W}$ than the updated CD86 V2.1. Furthermore, at the lower latitudes (e.g., Fig. 14a-c and Fig. 15a-c) the CD86 V2.1 results are now consistently lower than the MLS values between $1-5 \mathrm{hPa}$.

Next, we assess the zonal structure of the hindcast upper stratospheric ozone fields using the CHEM2D-OPP, GSFC2, and CD86 V2.1 photochemistry schemes. Figure 16 compares the NASA GMAO ozone analysis at the $5 \mathrm{hPa}$ level over the Northern Hemisphere for 12:00 UT on 7 February 2005 with the corresponding 132-h NOGAPS-ALPHA ozone fields. At this time, the $5 \mathrm{hPa}$ analysis (Fig. 16a) shows the lowest mixing ratios over a region displaced just off the pole in the longitude sector from approximately $60^{\circ} \mathrm{W}-$ $60^{\circ} \mathrm{E}$, while a region of higher ozone mixing ratios extends from mid-latitudes up across the pole. While all three ozone simulations in Fig. 16 capture this general structure, there are pronounced quantitative differences in the simulated high and low values compared to the analysis.

These differences are more clearly seen in Fig. 17, which plots the difference between the GMAO analysis (denoted as A) in Fig. 16a and the 132-h ozone hindcast fields (which we denote as the "forecast" value, F) using passive ozone
(Fig. 17a), CHEM2D-OPP (Fig. 17b), GSFC2 (Fig. 17c), and CD86 V2.1 (Fig. 17d). The passive ozone simulation exhibits higher A-F values over the Northern Hemisphere than the three simulations with parameterized photochemistry, indicating that in this case ozone transport alone will not accurately capture the evolution of upper stratospheric ozone over a 5 day period. Among the results using the three ozone photochemistry parameterizations plotted in Fig. 17, the CHEM2D-OPP results in Fig. 17b show the lowest overall values of A-F. The GSFC2 results (Fig. 17c) underpredict ozone mixing ratios by more than $1 \mathrm{ppmv}$ over an extended region from $10^{\circ} \mathrm{N}-90^{\circ} \mathrm{N}$. The CD86 V2.1 results (Fig. 17d) overpredict ozone values by more than 2 ppmv over a broad region of North America and the Canadian Arctic, in general agreement with the CD86 V2.1 results plotted in Figs. 11 and 15.

To further quantify the performance of the different photochemistry schemes used in NOGAPS-ALPHA for the 7 February test case, Fig. 18 plots the mean and root-meansquare (RMS) values of the A-F fields in Fig. 17 averaged over the latitude region from $10^{\circ} \mathrm{N}-90^{\circ} \mathrm{N}$ as a function of the forecast length from $144 \mathrm{~h}$ down to $24 \mathrm{~h}$ (suitable initial conditions were not available to perform the 120 -h and 12-h hindcasts). The unscaled ozone production rates in the GSFC1 scheme introduce large errors in the 132-h NOGAPS-ALPHA prognostic ozone at $5 \mathrm{hPa}$, both in terms 
(a) O3 ANL : $2005020712: 5 \mathrm{hPa}$

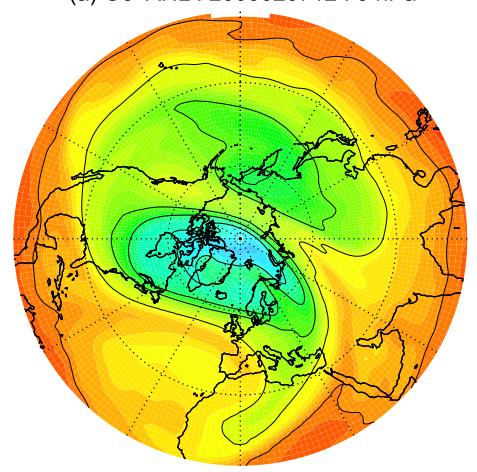

(c) O3 FCST : 2005020200_132: $5 \mathrm{hPa}:$ GSFC2

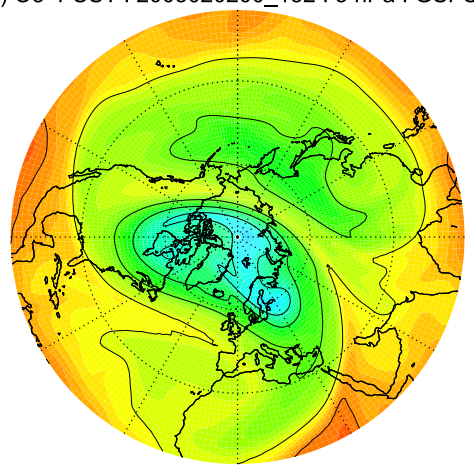

(b) O3 FCST : 2005020200_132: 5 hPa : CHEM2D

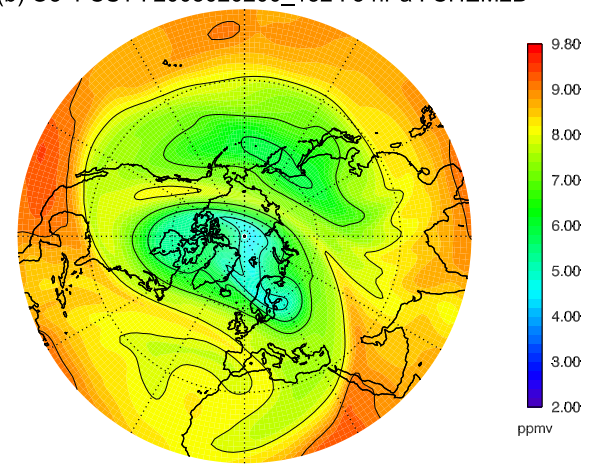

(d) O3 FCST : 2005020200_132: $5 \mathrm{hPa}:$ CDV2.1

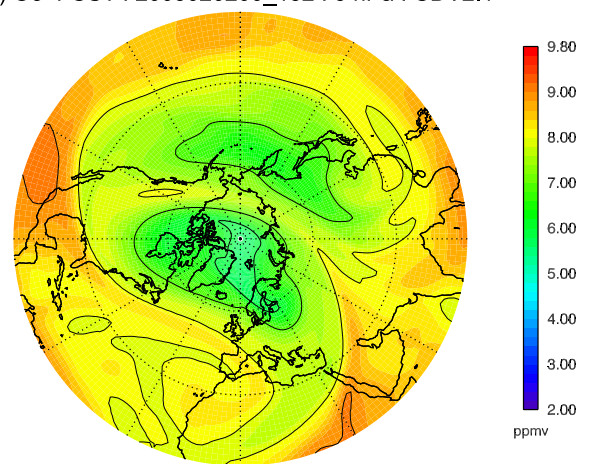

Fig. 16. Ozone mixing ratios (in ppmv) at $5 \mathrm{hPa}$ from (a) the NASA GMAO ozone analysis valid 12:00 UT on 7 February, 2005 , and NOGAPS-ALPHA 132-h ozone hindcasts initialized 00:00 UT on 2 February 2005 using (b) CHEM2D-OPP, (c) GSFC2, and (d) CD86 V2.1 ozone photochemistry parameterizations. Polar projection extends to $10^{\circ} \mathrm{N}$ latitude.

of mean and RMS differences. Of the 4 remaining photochemistry schemes tested, all produce similar results over forecast periods from $24-72 \mathrm{~h}$. The scaled GSFC2 and CD86 V1.0 results perform quite similarly over the entire range of forecast times plotted in Fig. 18, while CHEM2D-OPP produces the lowest values of mean and RMS A-F over forecast periods from $72-144 \mathrm{~h}$. Unlike the other photochemistry schemes tested in this case, both the mean (Fig. 18a) and the RMS (Fig. 18b) values of A-F from the CD86 V2.1 simulations tend to increase with increasing forecast length, such that at $132 \mathrm{~h}$ the RMS errors in the CD86 V2.1 case are comparable to the passive ozone case.

It is worth noting that the GMAO analysis is based primarily on SBUV ozone measurements, as is the 2D stratospheric ozone climatology of Fortuin and Kelder (1998) used for $r_{o}$ in CHEM2D-OPP. The NOGAPS-ALPHA simulations using CHEM2D-OPP will tend to relax the prognostic ozone fields towards SBUV-based climatological values in regions where ozone photochemistry is active and in the absence of large temperature or column ozone fluctuations. This may explain, in part, the relatively low mean A-F values from the CHEM2D-OPP results in Fig. 18a, and emphasizes how the choice of background reference state can influence the performance of a linearized ozone photochemistry scheme.

The results in Fig. 18 are based on a Northern Hemisphere wintertime ozone distribution for one particular date and time. A proper evaluation of the different photochemistry schemes would require an extended period of comparison with a full NWP/DA system (see, e.g., Geer et al., 2006b). Similarly, a detailed ensemble forecasting approach would be useful to quantify intrinsic model uncertainty in the prognostic ozone fields. Such computationally-intensive studies are beyond the scope of the present work. However, based on the results in Fig. 18, it is reasonable to conclude that most of the differences between the CHEM2D-OPP, GSFC2, and CD86 hindcast ozone profiles relative to the MLS observations in Figs. 14 and 15 equatorward of $50^{\circ} \mathrm{N}$ are within the range of typical forecast errors. The differences between these hindcast profiles and MLS observations poleward of $50^{\circ} \mathrm{N}$ (specifically, Fig. 14f and Figure 15e,f), on the other hand, exceed typical values of 132-h forecast errors in Fig. 18.

We now examine possible reasons why the CHEM2DOPP and CD86 V2.1 results tend to overestimate the ozone mixing ratios compared to MLS observations at $50^{\circ} \mathrm{N}$ and $60^{\circ} \mathrm{N}$ in Figs. 14 and 15. The fact that NOGAPS-ALPHA prognostic ozone profiles with a temperature sensitivity term (CHEM2D-OPP and CD86) show the poorest agreement with MLS ozone in the $2-20 \mathrm{hPa}$ region at the higher latitudes suggests that the problem could be related to deficiencies in the NOGAPS-ALPHA simulation of temperatures 
(a) $\mathrm{O} 3$ (A-F) : $2005020200132: 5 \mathrm{hPa}:$ PASS

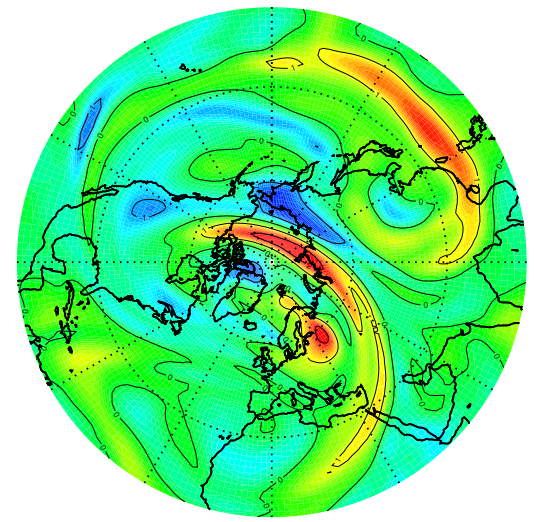

(c) O3 (A-F) : 2005020200_132 : $5 \mathrm{hPa}:$ GSFC2

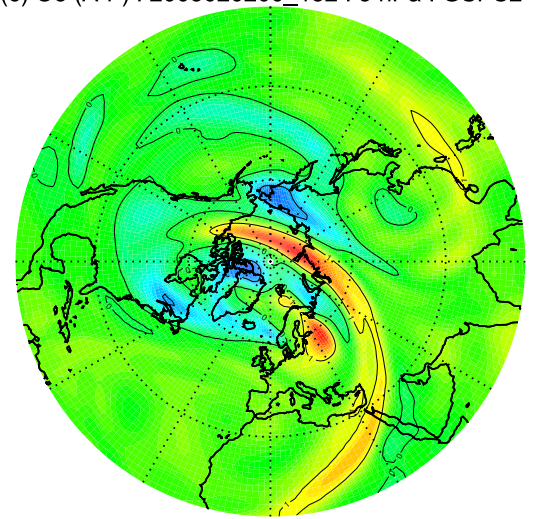

(b) O3 (A-F) : $2005020200132: 5 \mathrm{hPa}:$ CHEM2D

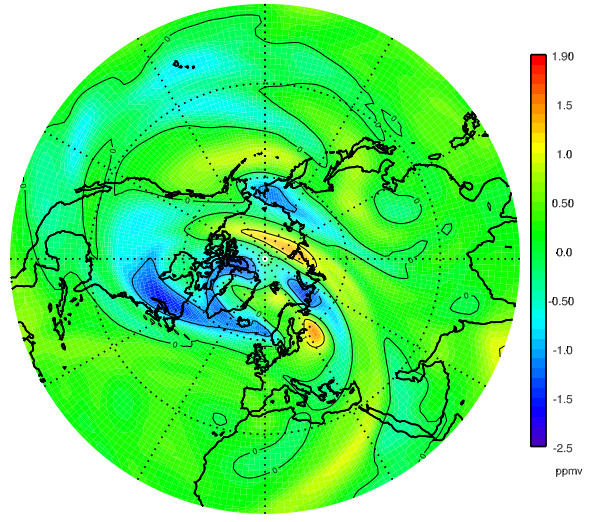

(d) O3 (A-F) : 2005020200_132:5 hPa : CDV2.1

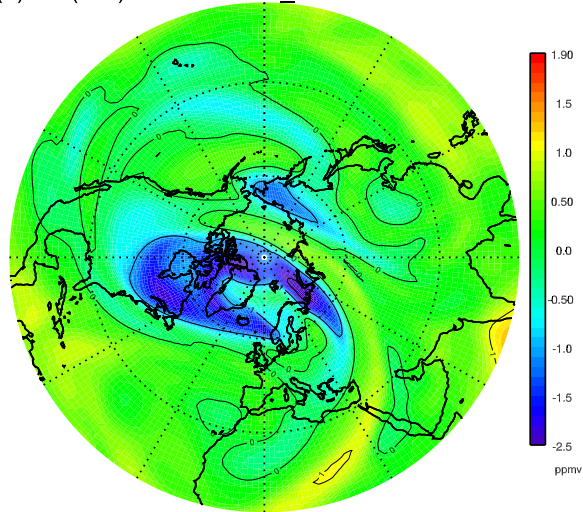

Fig. 17. Difference between ozone analysis (A) valid 12:00 UT on 7 February 2005 and forecast (F) mixing ratios (in ppmv) at $5 \mathrm{hPa}$ from NOGAPS-ALPHA 132-h ozone hindcasts initialized 00:00 UT on 2 February 2005 using (a) no photochemistry (passive), the (b) CHEM2D-OPP, the (c) GSFC2, and the (d) CD86 V2.1 ozone photochemistry parameterizations. Polar projection extends to $10^{\circ} \mathrm{N}$ latitude.
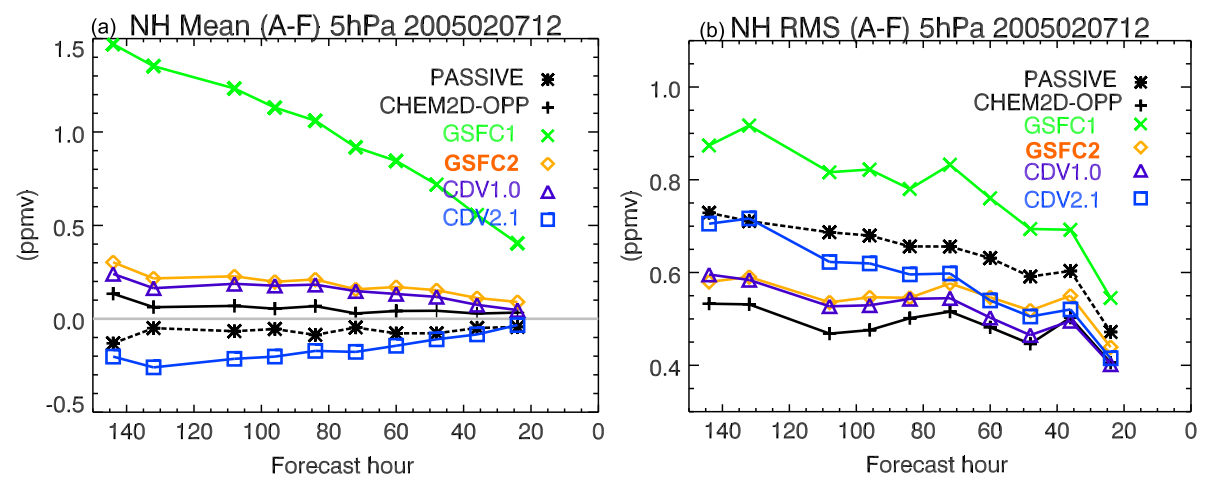

Fig. 18. The mean (a) and RMS (b) values of (A-F) from Fig. 17 computed from NOGAPS-ALPHA 24-144 h hindcasts over the latitude range $10^{\circ} \mathrm{N}-90^{\circ} \mathrm{N}$ using the CHEM2D-OPP (solid black line), GSFC1 (green crosses), GSFC2 (orange diamonds), CD86 V1.0 (purple triangles), and CD86 V2.1 (blue squares) photochemistry parameterizations along with the passive ozone hindcast (dashed black line). 

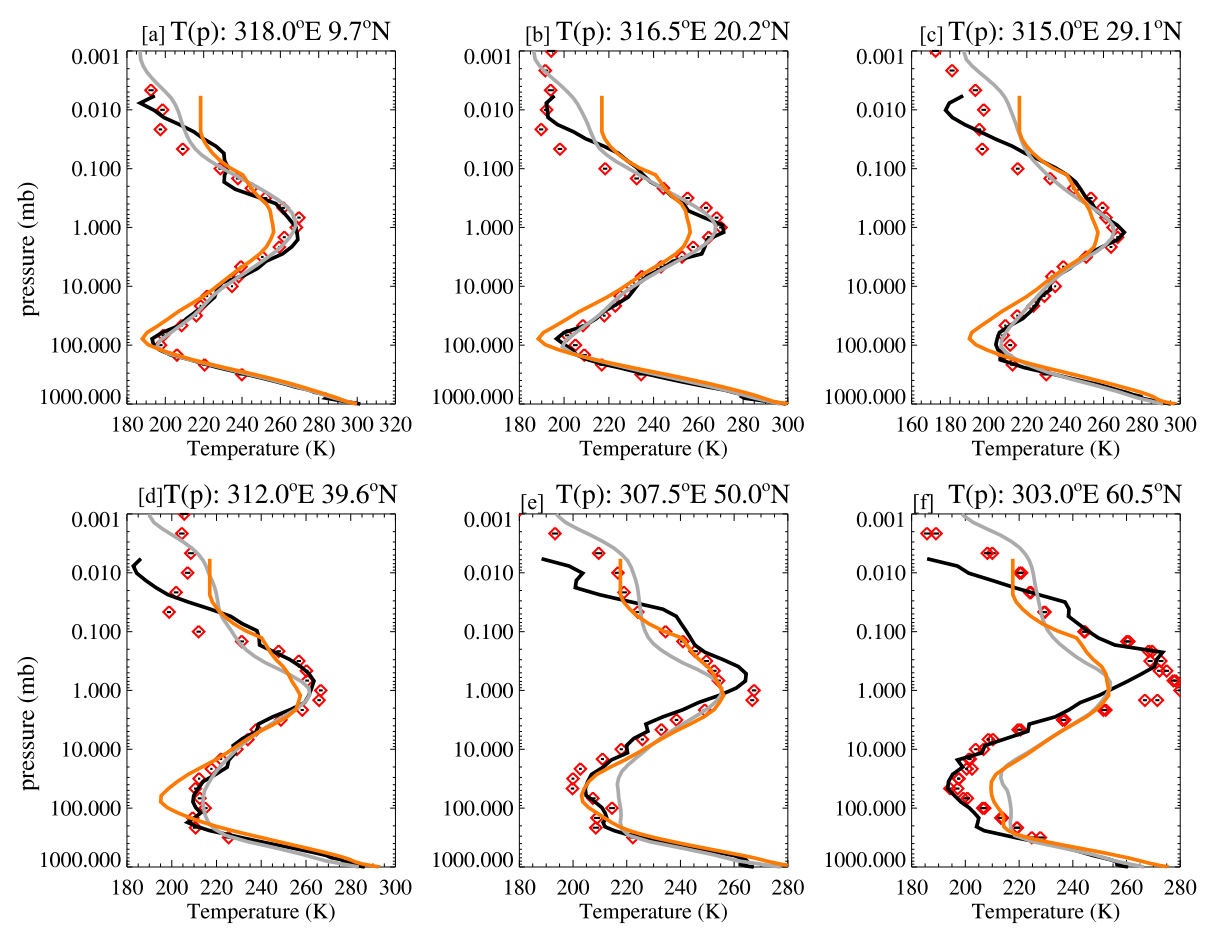

$$
\text { CIRA T } \text { CLim February }
$$

CD86 $\mathrm{T}_{\text {CLIM }}$ V2.1 NOGAPS Grid

NOGAPS $\mathrm{T}(\mathrm{x}, \mathrm{y}, \mathrm{p})$

AURA MLS

Fig. 19. Profiles of the 135-h NOGAPS-ALPHA hindcast temperatures (black curve) at each of the six locations along the 16:00 UT MLS flight track in Fig. 12. Also plotted are reference temperature profiles $T_{o}$ from the CHEM2D-OPP scheme (gray curve), $T_{o}$ profiles from the CD86 V2.1 scheme (orange curve), and Aura MLS temperature observations at 16:00 UT on 7 February 2005 (red points).
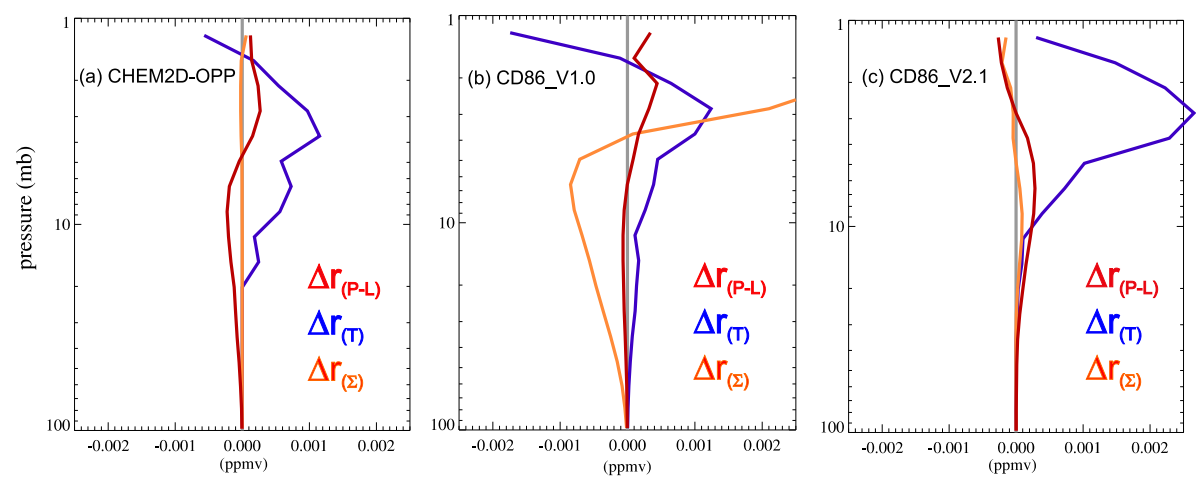

Fig. 20. Diagnostic calculations of $\Delta r_{(P-L)}$ (red curve), $\Delta r_{T}$ (blue curve), and $\Delta r_{\Sigma}$ (orange curve) for the 135-h (15:00 UT) NOGAPSALPHA hindcasts at $50^{\circ} \mathrm{N}, 52^{\circ} \mathrm{W}$, corresponding to Fig. 12e, using (a) CHEM2D-OPP, (b) CD86 V1.0, and (c) CD86 V2.1 photochemistry schemes. 
within and near the polar vortex on this date. For example, the NAVDAS analyses used to initialize NOGAPS-ALPHA are based on the operational NOGAPS T239L30 system and appear to have a cold bias over the polar regions (Eckermann et al., 2006). Furthermore, many stratospheric models have cold pole biases due to physical deficiencies and spatial resolution limits (Austin et al., 2003). Large, systematic temperature biases over time can manifest themselves as temperature perturbations $T^{\prime}$ in (4) that progressively relax ozone to a different state, even if the temperature coefficient itself is relatively small. Another possibility is that the model does not accurately simulate the time evolution of the polar vortex and associated dynamical features in the ozone distribution as the vortex is displaced southward during this stratospheric polar warming period.

To examine further the possible effect of a cold bias in NOGAPS-ALPHA hindcast temperatures on the parameterized ozone photochemistry at the high northern latitudes between 2-20 hPa, Fig. 19 plots temperature profiles from the 135-h NOGAPS-ALPHA hindcast at the six locations along the 7 February 16:00 UT MLS flight track in Fig. 12. Also plotted in Fig. 19 are climatological temperature profiles used to specify the reference state temperature $T_{o}$ in the CHEM2D-OPP (gray curve) and CD86 V2.1 (orange curve) ozone photochemistry schemes, and Aura MLS temperature profiles at each location for this date and time. The MLS temperatures come from the Version 1.5 standard product, which uses the $118 \mathrm{GHz}$ retrieval for levels between $316-1.41 \mathrm{hPa}$ and a combination of the $118 \mathrm{GHz}$ and $190 \mathrm{GHz}$ retrievals between $1-0.001 \mathrm{hPa}$. Preliminary comparisons with other satellite observations and meteorological analyses show a warm bias in MLS temperatures that increases from 1-2 K in the lower stratosphere to $2-4 \mathrm{~K}$ near $10 \mathrm{hPa}$; above $10 \mathrm{hPa}$ the MLS warm bias oscillates between 1-3 K (Froideveaux et al., 2006). At the lower latitudes (Fig. 19a-d), there is good agreement between the 135-h hindcast NOGAPS-ALPHA temperatures and Aura MLS temperatures below the $0.1 \mathrm{hPa}$ level where the CHEM2D-OPP photochemistry is applied.

At $50^{\circ} \mathrm{N}$ (Fig. 19e), NOGAPS-ALPHA hindcast temperatures in the upper stratosphere are consistently lower than MLS observations, with temperature differences of $\sim 5 \mathrm{~K}$ near $5 \mathrm{hPa}$ and $\sim 10 \mathrm{~K}$ near $1 \mathrm{hPa}$. Similarly, at $60^{\circ} \mathrm{N}$ (Fig. 19f), NOGAPS-ALPHA hindcast temperatures are colder than MLS observations by $\sim 10 \mathrm{~K}$ near $3 \mathrm{hPa}$ and $\sim 20 \mathrm{~K}$ near $1 \mathrm{hPa}$.

However, the temperature differences between the model and the reference state temperatures are of greater consequence for model prognostic ozone. Figure 19 shows that the 135-h NOGAPS-ALPHA hindcast temperatures are colder than the CIRA86 climatological values used to specify $T_{o}$ in CHEM2D-OPP. At $50^{\circ} \mathrm{N}$ and $20 \mathrm{hPa}$, where NOGAPSALPHA prognostic ozone values are higher than MLS observations (Figs. 12 and 13), NOGAPS-ALPHA temperatures are $10-20 \mathrm{~K}$ colder than $T_{o}$ (gray curve in Fig. 19). As the following discussion shows, this difference between model and reference state temperatures produces a high ozone bias in the model prognostic ozone fields through the temperature term in Eq. (4).

Figure 5 shows very small negative values of the temperature coefficient $\left.\frac{\partial(P-L)}{\partial T}\right|_{o}$ are present in the stratosphere at high northern latitudes during winter due to the temperature dependence of the odd oxygen loss rates, which continue to operate in polar night. The combination of large (10-20 K) negative temperature perturbations and longer lifetimes $\left(\tau_{\mathrm{O}_{3}}\right)$ (Fig. 2) produces a large positive ozone mixing ratio tendency in the lower and middle stratosphere. To illustrate this effect we perform a series of off-line single column diagnostic calculations to determine the relative roles of the net tendency, temperature, and column ozone coefficients on the model prognostic ozone. From Eqs. (9-12), over a given model time step $\Delta t$ the photochemistry relaxes ozone mixing ratios $r$ to the current steady-state ozone mixing ratio $r^{s s}$ at the photochemical relaxation rate $\tau_{\mathrm{O}_{3}}$. We can examine the contribution to the steady-state mixing ratio from each of the three terms in (9) by defining the following relations:

$$
\begin{aligned}
& r_{(P-L)}^{s s}=r_{o}+(P-L)_{o} \tau_{\mathrm{O}_{3}} \\
& r_{T}^{s s}=r_{o}+\left[\left.\frac{\partial(P-L)}{\partial T}\right|_{o}\left(T-T_{o}\right)\right] \tau_{\mathrm{O}_{3}} \\
& r_{\Sigma}^{s s}=r_{o}+\left[\left.\frac{\partial(P-L)}{\partial \Sigma}\right|_{o}\left(\Sigma-\Sigma_{o}\right)\right] \tau_{\mathrm{O}_{3}}
\end{aligned}
$$

From (12), we can compute the change in ozone mixing ratio $\Delta r=r(t+\Delta t)-r(t)$ over the model time step $\Delta t$ for each of the contributions in (13), i.e.:

$$
\begin{aligned}
& \Delta r_{P-L}=\left[r_{P-L}^{s s}-r(t)\right]\left[\frac{\frac{\Delta t}{\tau_{\mathrm{O}_{3}}}}{1+\frac{\Delta t}{\tau_{\mathrm{O}_{3}}}}\right] \\
& \Delta r_{T}=\left[r_{T}^{s s}-r(t)\right]\left[\frac{\frac{\Delta t}{\tau_{\mathrm{O}_{3}}}}{1+\frac{\Delta t}{\tau_{\mathrm{O}_{3}}}}\right] \\
& \Delta r_{\Sigma}=\left[r_{\Sigma}^{s s}-r(t)\right]\left[\frac{\frac{\Delta t}{\tau_{\mathrm{O}_{3}}}}{1+\frac{\Delta t}{\tau_{\mathrm{O}_{3}}}}\right]
\end{aligned}
$$

Figure 20 compares the individual terms $\Delta r_{P-L}, \Delta r_{T}$, and $\Delta r_{\Sigma}$, in (14) at $50^{\circ} \mathrm{N}, 52^{\circ} \mathrm{W}$ (e.g., Figure $12 \mathrm{e}$ ) for a value of $\Delta t=1 \mathrm{~h}$. Each term uses 135-h NOGAPS-ALPHA hindcast ozone mixing ratio and temperature profiles to specify $r, T$, and $\Sigma$. Figure 20a plots $\Delta r_{P-L}$ (red curve), $\Delta r_{T}$ (blue curve), and $\Delta r_{\Sigma}$ (orange curve) based on the CHEM2DOPP values of the photochemistry coefficients and associated reference state climatologies (FK98 for $r_{o}$, CIRA86 for $T_{o}$ ). The profiles show that the CHEM2D-OPP temperature term $\Delta r_{T}$ is the leading contributor to a net increase in ozone, which is slightly offset by a negative contribution from $\Delta r_{P-L}$ altitudes below the $4 \mathrm{hPa}$ level $(\sim 38 \mathrm{~km})$. Figures $20 \mathrm{~b}$ and $20 \mathrm{c}$ plot the same terms computed using the CD86 V1.0 and CD86 V2.1 coefficients and climatologies, 

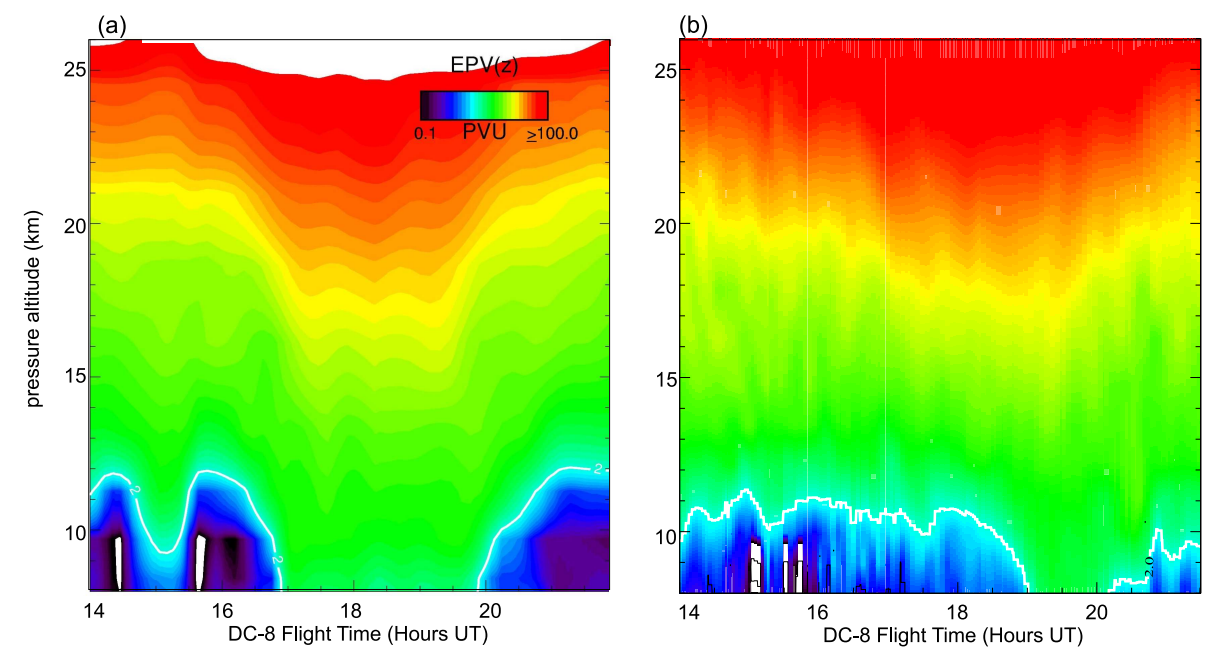

Fig. 21. Cross section of Ertel's potential vorticity in potential vorticity units (PVU) along the DC8 flight path of 7 February 2005 , derived from (a) NASA GMAO meteorological analyses (data courtesy of NASA Goddard Space Flight Center, Code 613.3), and from (b) 138-h T239L60 NOGAPS-ALPHA hindcast vorticity fields initialized 00:00 UT 2 February 2005 and valid at 18:00 UT 7 February. White contour denotes the 2 PVU contour indicating the approximate tropopause altitude.
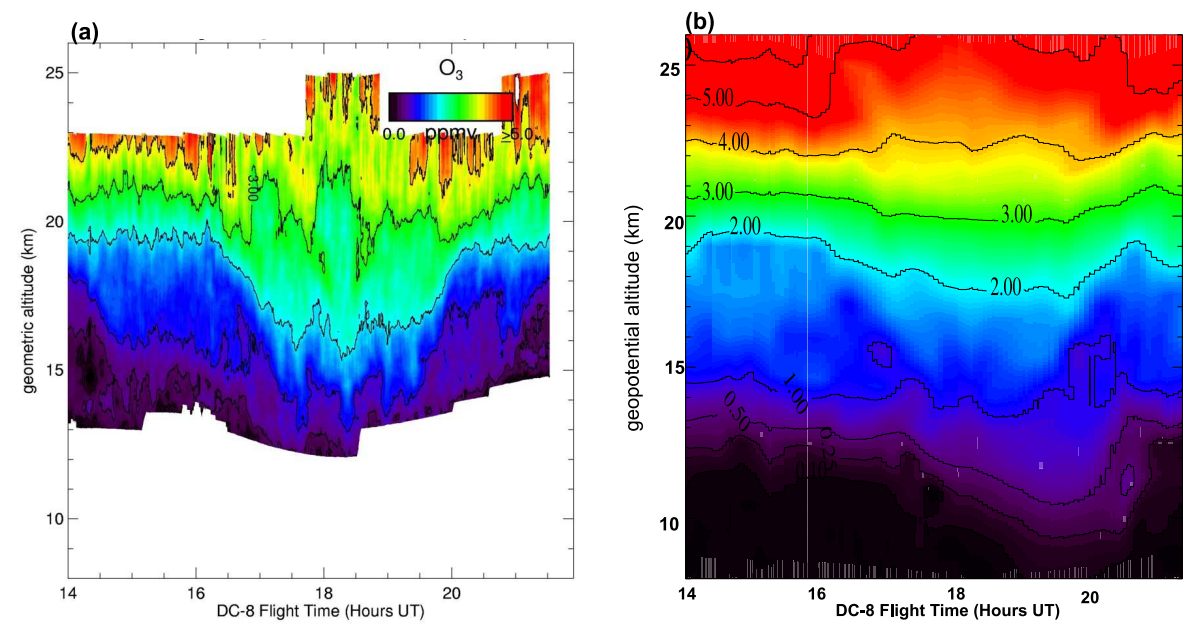

Fig. 22. Ozone mixing ratios in ppmv from (a) the AROTAL instrument aboard the NASA DC8 flight on 7 February 2005 , plotted versus geometric altitude and from (b) a 138-h T239L60 NOGAPS-ALPHA ozone hindcast with CHEM2D-OPP photochemistry plotted versus geopotential height at locations along the DC8 flight track. 
respectively. We see that the CD86 V1.0 scheme in Fig. 20b produces positive values of the $\Delta r_{T}$ term that are comparable to the CHEM2D-OPP value in Fig. 20a, and $\Delta r_{\Sigma}$ values that are negative below the $5 \mathrm{hPa}$ level and then rapidly become large and positive above the $5 \mathrm{hPa}$ level. These large $\Delta r_{\Sigma}$ values are present at all latitudes and are the source of the jagged vertical structure above $10 \mathrm{hPa}(\sim 30 \mathrm{~km})$ seen in the NOGAPS-ALPHA hindcast ozone profiles generated with the CD86 V1.0 scheme (Figs. 12 and 13). The updated CD86 V2.1 results (Fig. 20c) show a large positive temperature tendency peaking near $3 \mathrm{hPa}$ but, unlike the CD86 V1.0 results in Fig. 20b, there is now little contribution from the column term.

Values of the column sensitivity term $\left.\frac{\partial(P-L)}{\partial \Sigma}\right|_{o}$ in the upper stratosphere are smaller in the CD86 V2.1 scheme than in the CD86 V1.0 scheme. This explains the smoother ozone profiles above the $10 \mathrm{hPa}$ level in the hindcasts generated with the CD86 V2.1 scheme (Figs. 14 and 15). A consequence of the smaller ozone column term in the CD86 V2.1 scheme is that there is no longer a large negative column perturbation offsetting the positive temperature perturbation. As a result, the CD86 V2.1 ozone hindcasts at $50^{\circ} \mathrm{N}, 52^{\circ} \mathrm{W}$ (Fig. 14e) show better agreement with the CHEM2D-OPP results than the CD86 V1.0 results (Fig. 12e).

The fact that the 135-h T79L60 NOGAPS-ALPHA ozone hindcasts at $50^{\circ} \mathrm{N}$ overestimate the ozone mixing ratios between $30-10 \mathrm{hPa}$, as compared to the 16:00 UT MLS observations (see Figs. 12e and 14e), regardless of the photochemistry parameterization suggests that the model dynamics may not be accurately simulating some small-scale structure in the ozone profile at this location. We examine this possibility further by comparing higher resolution T239L60 NOGAPSALPHA ozone hindcasts with airborne ozone measurements from the 7 February DC8 flight. To illustrate the dynamical conditions encountered by the DC8 aircraft on this date, Fig. 21a plots values of Ertel's potential vorticity (EPV) between $15-25 \mathrm{~km}$ derived from NASA GMAO meteorological analyses along the 7 February 2005 DC8 flight track. At 16:00 UT (way point 4 in Fig. 10), the DC8 encounters increasing EPV values, indicating that the aircraft has crossed the vortex "collar" region and is entering the high-EPV air within the polar vortex. Figure 21b plots EPV from a 138-h T239L60 NOGAPS-ALPHA hindcast valid at 18:00 UT on 7 February. The sharp changes in EPV seen in the GMAO EPV fields as the DC 8 crosses the vortex collar region after 16:00 UT and again just prior to 20:00 UT are not as welldefined in the NOGAPS-ALPHA EPV fields.

To illustrate the relationship between EPV and ozone along the 7 February flight track, Fig. 22a plots the ozone mixing ratio profiles measured with the Airborne Raman Ozone Temperature and Aerosol Lidar (AROTAL) (Burris et al., 2002) on board the DC8. AROTAL profiles within the vortex and collar regions are characterized by highly localized regions of low ozone between $20-25 \mathrm{~km}$. Figure $22 \mathrm{~b}$ displays a contour map of T239L60 NOGAPS-ALPHA 138- $\mathrm{h}$ hindcast ozone profiles using the CHEM2D-OPP scheme, valid at 18:00 UT, following the DC8 flight path. Despite the higher horizontal resolution in the T239 configuration, the NOGAPS-ALPHA hindcast ozone fields do not reproduce the dynamical structure in the AROTAL ozone profiles (Fig. 22a). In particular, the model does not capture the observed localized regions of lower ozone mixing ratio ( $<4$ ppmv) between 22-25 km from 16:00 UT-18:00 UT in Fig. 22a. Thus the high ozone values in the 16:00 UT NOGAPS-ALPHA hindcasts for at $50^{\circ} \mathrm{N}$ relative to MLS observations in Figs. 12e and 14e are also due in part to difficulties in modeling small-scale dynamical features in the ozone distribution related to horizontal and vertical mixing in the region of the vortex collar.

\subsection{CHEM2D-OPP in NOGAPS-ALPHA: climate mode}

Since the time scale for ozone photochemistry is quite long (>100 days) in the lower stratosphere (see Fig. 2), any systematic biases in the linearized photochemistry parameterization should not affect model prognostic ozone for typical NWP/DA applications in this region. In the NWP case, forecasts are typically 5-10 days in length, a period much shorter than the effective ozone relaxation time in the lower stratosphere. In the DA case, frequent updates of assimilated ozone fields with observations (e.g., every $6 \mathrm{~h}$ ) should correct any systematic biases introduced by the parameterized photochemistry. NWP/DA systems are therefore better suited for testing CHEM2D-OPP in the middle and upper stratosphere where the ozone distribution is controlled largely through photochemical effects (Geer et al., 2006b). Model simulations over seasonal time scales (i.e., longer than $\sim 100$ days) are needed to quantify possible systematic biases in CHEMD-OPP affecting lower stratospheric ozone.

To fully test CHEM2D-OPP performance throughout the entire stratosphere, we have conducted a 1-year free running T79L60 NOGAPS-ALPHA simulation in climate mode. This particular experiment was initialized with archived MVOI and STRATOI meteorological fields and GMAO ozone for 20 December 2001 using the climate run configuration described in Sect. 3.1. The CHEM2D-OPP photochemistry was applied to NOGAPS-ALPHA prognostic ozone fields between $500-0.1 \mathrm{hPa}$. Outside of this altitude range the prognostic ozone fields were constrained to model climatology.

Earlier NOGAPS-ALPHA tests of CHEM2D-OPP in climate mode produced unrealistically large values of zonal mean prognostic ozone from $1-10 \mathrm{hPa}$ near $65^{\circ}$ latitude in both hemispheres during late winter and early spring (not shown). This effect was caused by the combination of an overall warm bias in the CIRA86 stratospheric temperatures and the cold bias in model temperatures at the high winter latitudes (see Sect. 4.1). Because the sign of the temperature term is negative (Fig. 5), the persistent large negative temperature perturbations $\left(T-T_{o}\right)$ produced large positive ozone 

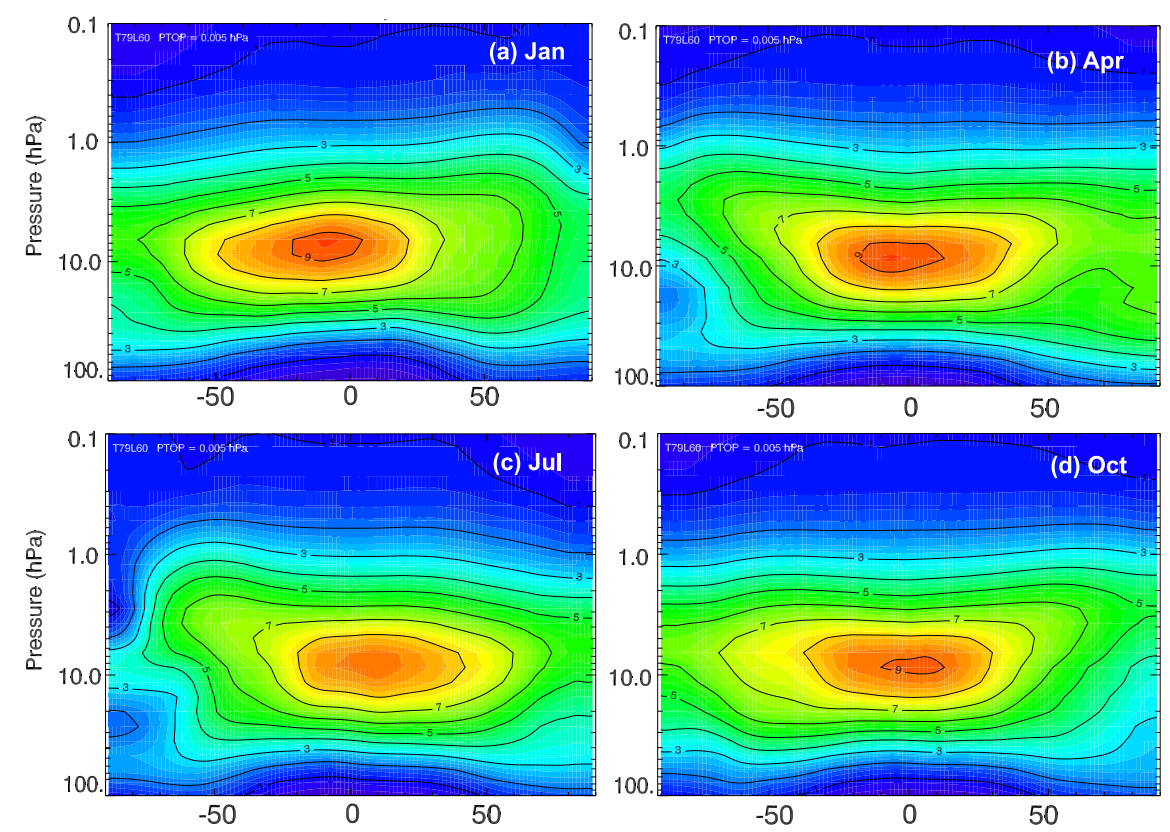

Fig. 23. Monthly mean ozone mixing ratios (ppmv) from a free-running T79L60 NOGAPS-ALPHA climate experiment using CHEM2DOPP photochemistry with a modified temperature term for (a) January, (b) April, (c) July, and (d) October.
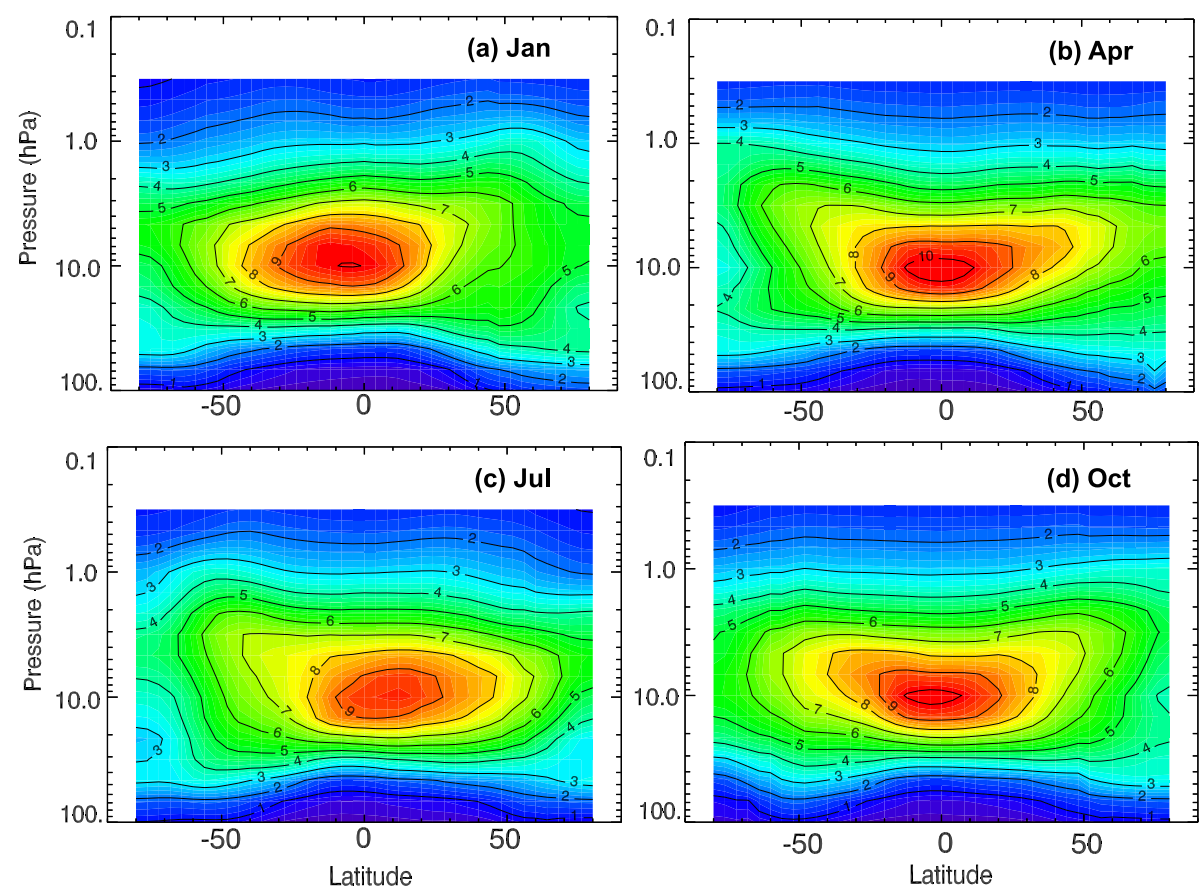

Fig. 24. Monthly mean ozone mixing ratios (ppmv) from the extended URAP climatology for (a) January, (b) April, (c) July, and (d) October. 
perturbations over the course of the winter. A similar effect was noted over high southern latitudes during the AugustNovember period in an extended data assimilation run using CHEM2D-OPP (Geer et al., 2006b).

Normally, the relaxation term in (4) would quickly act to reduce these erroneously high ozone values between 1$10 \mathrm{hPa}$. However, in polar night, the ozone relaxation time $\tau_{\mathrm{O}_{3}}$ at these altitudes is quite long (Fig. 2), allowing the effects of these systematic temperature biases to grow unchecked in the long-term climate experiments until later in spring when the ozone relaxation time becomes much shorter. To eliminate the effect of systematic highlatitude temperature biases on NOGAPS-ALPHA prognostic ozone in climate mode during polar night, the CHEM2DOPP scheme was modified so that the temperature term is set to zero at night poleward of $65^{\circ}$ latitude.

Figure 23 plots monthly zonal mean values of NOGAPSALPHA prognostic ozone for January, April, July, and October with the modified CHEM2D-OPP photochemistry. For comparison, Fig. 24 plots corresponding monthly mean ozone mixing ratios from the extended URAP ozone climatology. There is generally good agreement between the monthly mean NOGAPS-ALPHA and URAP ozone fields. Areas of poor agreement occur in the lower stratosphere at high southern latitudes in July, when the model underpredicts zonal mean ozone mixing ratios, and in October when the model overpredicts zonal mean ozone mixing ratios. In the July case, the disagreement is the result of model dynamics producing both excessive descent of ozone-poor air within the polar vortex between $10-1 \mathrm{hPa}$ and inadequate horizontal mixing by planetary wave activity in the lower stratosphere near $100 \mathrm{hPa}$. In the October case, the model ozone does not capture the springtime ozone hole due to the lack of heterogeneous chemical effects in the parameterized photochemistry.

Another area of disagreement between the model and URAP climatological ozone values is at the peak of the ozone profile over the tropical regions, where the model values are consistently $1-2$ ppmv less than the peak URAP value. This can be attributed to the use of the FK98 ozone climatology to specify the reference state mixing ratio values $r_{o}$. As discussed in Sect. 2, the FK98 climatology tends to underestimate the peak ozone value as compared to various UARS ozone measurements. Since the ozone relaxation time $\tau_{\mathrm{O}_{3}}$ is short in the tropical upper stratosphere throughout the year, CHEM2D-OPP is consistently relaxing the prognostic ozone fields to a reference state with a peak value lower than the average conditions represented in the URAP climatology. Additional climate simulations using different start dates and initial conditions produced results very similar to those in Fig. 23. The choice of reference ozone distribution $r_{o}$ in CHEM2D-OPP appears to be of more importance than the choice of initial conditions for NOGAPS-ALPHA simulations of one month or longer.

\section{Conclusions}

This study provides a detailed description of a new linearized parameterization of gas-phase ozone photochemistry, known as CHEM2D-OPP, which is based on output from the NRL CHEM2D photochemical transport model. As with earlier schemes, CHEM2D-OPP consists of four coefficients describing the residual ozone photochemical tendency $(P-L)$ and its sensitivity to local changes in ozone mixing ratio, temperature, and overhead ozone column amount (see Figs. 1, 2, 5, and 6). CHEM2D-OPP performance was tested using short-term (hindcast) and long-term (climate) NOGAPS-ALPHA model simulations and the results compared with both observations and results from identical model simulations using earlier ozone photochemistry parameterizations.

In the hindcast experiments, we compared NOGAPSALPHA prognostic ozone fields at $5 \mathrm{hPa}$ issued over a range of forecast times from 24-144h with NASA GMAO ozone analyses over the Northern Hemisphere for the 7 February 2005 test case to quantify the performance of the different photochemistry schemes relative to each other and to the case with no ozone photochemistry (i.e., passive ozone). In terms of the mean and RMS values of A-F (analysis - forecast), the adjusted production rates in the GSFC2 scheme are an improvement over the GSFC1 rates. The CHEM2D-OPP, GSFC2, and CD86 (V1.0 and V2.1) schemes all yield similar performance over forecast lengths from 24-72 h. Both GSFC2 and CD86 V1.0 exhibit similar performance from 24-144 h, while the CD86 V2.1 performance noticeably degrades at forecast times longer than $72 \mathrm{~h}$. Overall, the CHEM2D-OPP scheme produces the lowest mean and RMS values of $\mathrm{A}-\mathrm{F}$ for this case.

In comparing NOGAPS-ALPHA hindcast ozone profiles with Aura MLS observations, we find that the updated CD86 V2.1 scheme (Figs. 14 and 15) does not produce the artifacts in the ozone profile above $10 \mathrm{hPa}$ that are seen in the CD86 V1.0 results (Figs. 12 and 13) due to a much smaller ozone column sensitivity. This smaller ozone column sensitivity, however, no longer offsets the large positive ozone tendencies at latitudes poleward of $50^{\circ} \mathrm{N}$ produced by the temperature sensitivity term (Fig. 20). The result is that the ozone hindcasts using the CD86 V2.1 photochemistry parameterization now exhibit a high bias poleward of $50^{\circ} \mathrm{N}$ near $10 \mathrm{hPa}(\sim 30 \mathrm{~km})$, and a low bias equatorward of $30^{\circ} \mathrm{N}$ near $1 \mathrm{hPa}(\sim 50 \mathrm{~km})$, relative to both the MLS observations (Figs. 14 and 15) and hindcasts using CD86 V1.0 photochemistry (Figs. 12 and 13). In this regard, the CHEM2DOPP photochemistry provides better agreement with MLS observations at and above $10 \mathrm{hPa}$ than either version of the CD86 photochemistry for the 7 February 2005 test case presented here.

Results from both the NOGAPS-ALPHA hindcast and climate experiments show that the performance of the CHEM2D-OPP scheme can depend on the choice of clima- 
tology to specify the reference state temperature distribution $\left(T_{o}\right)$. A warm bias in the CIRA86 temperatures (Randel et al., 2004), when combined with model temperatures that are consistently too cold at high winter latitudes, produced large negative temperature perturbations that led to a high ozone bias at high latitudes in winter. Modifying the CHEM2DOPP temperature term such that it is set to zero during polar night eliminated this high latitude ozone bias in the year-long NOGAPS-ALPHA simulation. However, a more satisfactory long-term solution would be to eliminate the systematic highlatitude temperature biases by using an updated temperature climatology and improving the model dynamics at high latitudes in winter.

Because linearized ozone photochemistry depends on the reference state ozone and temperature distributions, we are currently investigating methods to improve CHEM2D-OPP performance for both NWP and DA applications through the choice of different reference state ozone mixing ratio and temperature distributions. For example, as Fig. 19 shows, there can be very large differences (i.e., $20 \mathrm{~K}$ or more) between the background temperature distributions represented by conventional zonal mean climatologies and observed temperatures at high winter latitudes during a stratospheric warming period. These large differences approach the upper limit of temperature perturbations over which the linearization approximation is valid for the ozone photochemical tendency equation. We are conducting ozone DA system tests using "adaptive" time-varying background ozone and temperature distributions computed directly from analyses in place of the conventional climatologies in CHEM2D-OPP in order to determine if the adaptive climatologies can reduce systematic differences between forecast and observed ozone.

Despite the inherent limitations of replacing a complex, nonlinear system of photochemical reactions for ozone with a simpler linearized approximation, constraints on computing resources preclude a full treatment of ozone photochemistry in operational high altitude NWP and DA systems for the time being. Furthermore, there are a wide range of middle atmospheric modeling applications where a fully coupled photochemical model is not required. This study demonstrates the utility of CHEM2D-OPP for a fast, accurate description of ozone photochemistry in both NWP and climate applications. As a result of this and other pilot studies, a version of CHEM2D-OPP was integrated into the operational NCEP GFS on 22 August, 2006 as a replacement for the original GSFC photochemistry parameterization.

We conclude by presenting a short description of proposed modifications to the CHEM2D-OPP formulation that are likely to offer improved capabilities for these types of applications. One proposed modification of CHEM2D-OPP will account for the diurnal cycle in ozone above the $0.1 \mathrm{hPa}$ level. This would improve NOGAPS-ALPHA mesospheric shortwave heating rate calculations and correct our model's high temperature bias compared to Aura MLS temperatures in this region (e.g., Sassi et al., 2005). Another proposed modification is to include the direct effects of variations in solar irradiance. This term would quantify the ozone response to small changes in solar UV at wavelengths important for ozone photochemistry, such as those observed over the 27-day solar rotation period and, possibly, the longer 11year cycle. Finally, CHEM2D-OPP can be modified to account for the effects of ozone losses via heterogeneous reactions on polar stratospheric cloud (PSC) particles, ideally by using an additional "cold tracer" in NOGAPS-ALPHA (Hadjinicolaou and Pyle, 2004) to track the temperature history of air parcels relative to a specified PSC activation temperature. We anticipate testing this approach using CHEM2D-OPP in an ozone assimilation system to determine how the parameterization of heterogeneous ozone loss impacts the quality of the ozone assimilation in the polar lower stratosphere.

To obtain the CHEM2D-OPP coefficients and view the latest version information, see http://uap-www.nrl.navy.mil/ dynamics/html/chem2dopp/chem2d_opp.html.

\section{Appendix A}

\section{Calculation of CHEM2D-OPP coefficients}

This appendix describes the details of the CHEM2D model calculations used to produce the CHEM2D-OPP linearized photochemical coefficients in (4). CHEM2D model calculations of the net odd oxygen tendency $(P-L)_{\mathrm{O}_{\mathrm{x}}}$ account for the production of odd oxygen by photolysis of molecular oxygen and odd oxygen loss through reactions involving oxides of hydrogen $\left(\mathrm{HO}_{\mathrm{x}}\right)$, nitrogen $\left(\mathrm{NO}_{\mathrm{x}}\right)$, chlorine $\left(\mathrm{ClO}_{\mathrm{x}}\right)$, and bromine $\left(\mathrm{BrO}_{\mathrm{x}}\right)$. Neglecting transport, a simplified version of the odd oxygen continuity equation can be written in the form (see, e.g., Stolarski and Douglass, 1985):

$$
\begin{gathered}
\frac{\partial\left[\mathrm{O}_{\mathrm{x}}\right]}{\partial t}=2 J_{2}\left[\mathrm{O}_{2}\right]-\left(k_{1}[\mathrm{OH}]+k_{2}\left[\mathrm{HO}_{2}\right]\right)[\mathrm{O}]-2 k_{3}\left[\mathrm{NO}_{2}\right][\mathrm{O}] \\
-2 k_{4}[\mathrm{ClO}][\mathrm{O}]-k_{5}[\mathrm{BrO}][\mathrm{O}]-k_{6}[\mathrm{O}]\left[\mathrm{O}_{3}\right]- \\
\left(k_{7}[\mathrm{OH}]+k_{8}\left[\mathrm{HO}_{2}\right]\right)\left[\mathrm{O}_{3}\right]-k_{9}[\mathrm{Br}]\left[\mathrm{O}_{3}\right] \quad(\mathrm{A}, 1)
\end{gathered}
$$

where it is assumed that $[\mathrm{ClO}]$ and $[\mathrm{Cl}]$ are in equilibrium, as are $\left[\mathrm{NO}_{2}\right]$ and $[\mathrm{NO}]$, and minor reactions (e.g., $\mathrm{ClO}+h v \rightarrow \mathrm{Cl}+\mathrm{O}, \mathrm{CH}_{3} \mathrm{O}_{2}+\mathrm{NO} \rightarrow \mathrm{CH}_{3} \mathrm{O}+\mathrm{NO}_{2}$ ) are neglected (Brasseur and Solomon, 1986). Although the CHEM2D model contains the full set of odd oxygen reactions, for simplicity's sake, we have only listed the dominant loss mechanisms in (A1).

Table A1 lists these nine dominant odd oxygen loss reactions and their rate constants used to compute the odd oxygen photochemical relaxation time $\tau_{\mathrm{O}_{\mathrm{x}}}$. The loss rates for these reactions are represented as $L_{i}, i=1 \ldots 9$. The CHEM2D values of $L_{i}$ for each reaction are output at all model latitudes and altitudes on the fifteenth day of each month. Figure A1 plots CHEM2D vertical profiles of $L_{i}$ over the equator on 15 March in units of $\mathrm{cm}^{-3} \mathrm{~s}^{-1}$. The odd-oxygen relaxation time $\tau_{\mathrm{O}_{\mathrm{x}}}$ is determined from the sum of the loss rates from all 


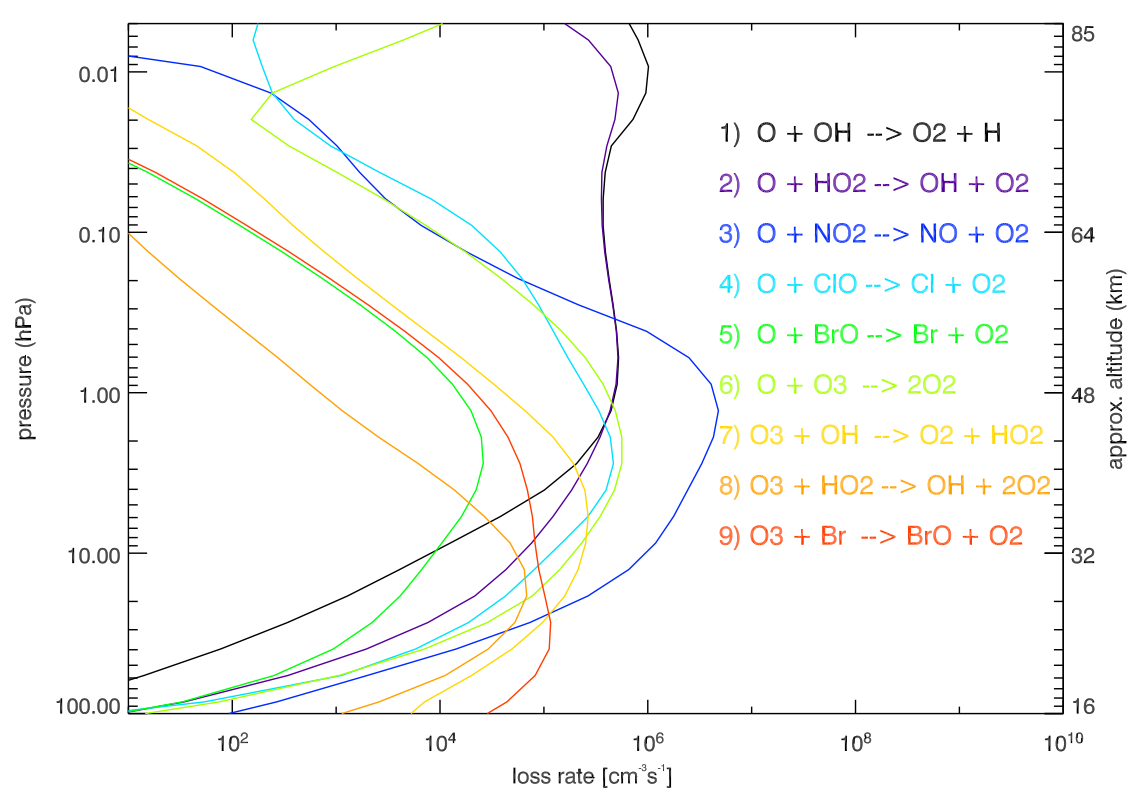

Fig. A1. Vertical profiles of individual CHEM2D odd oxygen loss rates $\left(\mathrm{cm}^{-3} \mathrm{~s}^{-1}\right)$ for 15 March over the equator, used to compute the photochemical relaxation time $\tau_{\mathrm{O}_{3}}$.
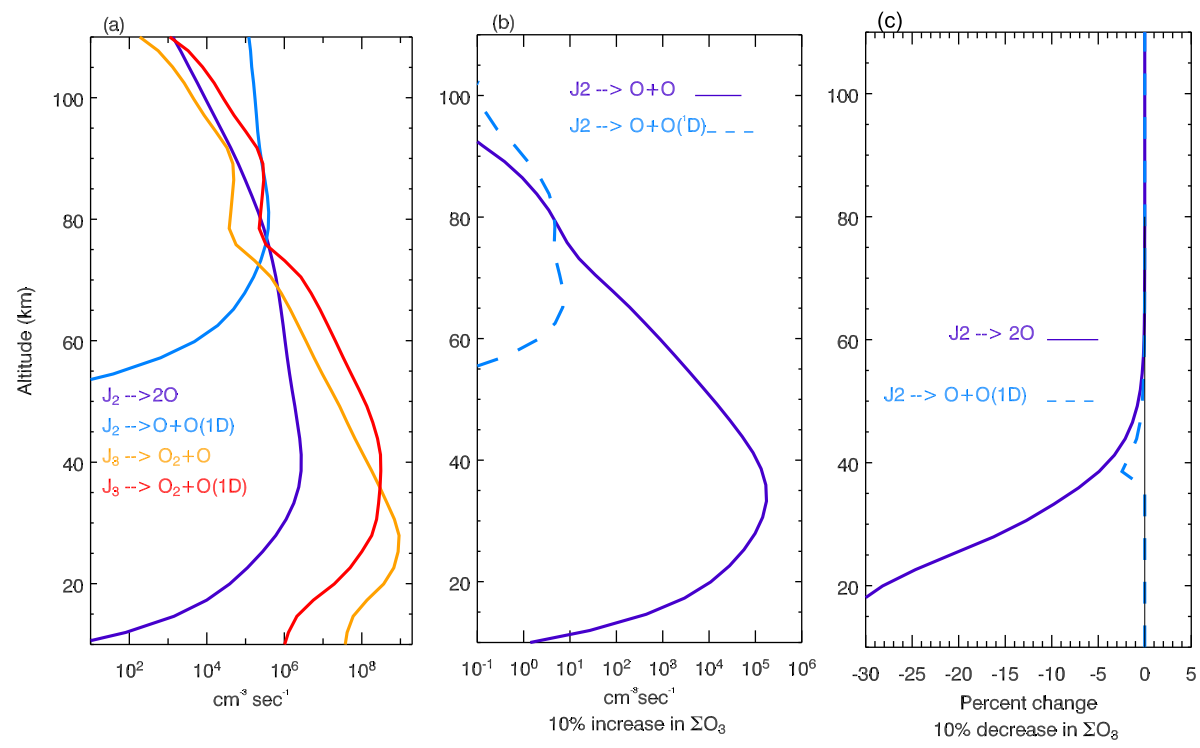

Fig. A2. (a) Vertical profiles of CHEM2D $J_{2}$ and $J_{3}$ photolysis terms for production of atomic oxygen in both ground state and excited state $\left(O\left({ }^{1} D\right)\right)$ for March conditions at $30^{\circ} \mathrm{N}$; (b) the absolute reduction in $J_{2}$ from (a) for an imposed $10 \%$ increase in overhead column ozone at each model vertical level; (c) as in (b) but for the percentage reduction in $J_{2}$. 
Table A1.

Table A1. CHEM2D Odd Oxygen Loss Reactions for Computing $\tau_{\mathrm{O}_{3}}$

\begin{tabular}{|c|c|c|c|}
\hline & Reaction & $\left(\alpha_{i}\right)$ & $k, \mathrm{~cm}^{3}$ molecule $\mathrm{s}^{-1} \mathrm{~s}^{-1}$ \\
\hline 1. & $\mathrm{O}+\mathrm{OH} \rightarrow \mathrm{O}_{2}+\mathrm{H}$ & (1) & $2.2 \times 10^{-11} e^{-120 / T}$ \\
\hline 2. & $\mathrm{O}+\mathrm{HO}_{2} \rightarrow \mathrm{OH}+\mathrm{O}_{2}$ & (1) & $3.0 \times 10^{-11} e^{-200 / T}$ \\
\hline 3. & $\mathrm{O}+\mathrm{NO}_{2} \rightarrow \mathrm{NO}+\mathrm{O}_{2}$ & (2) & $5.6 \times 10^{-12} e^{180 / T}$ \\
\hline 4. & $\mathrm{O}+\mathrm{ClO} \rightarrow \mathrm{Cl}+\mathrm{O}_{2}$ & (2) & $3.0 \times 10^{-11} e^{-70 / T}$ \\
\hline 5. & $\mathrm{O}+\mathrm{BrO} \rightarrow \mathrm{Br}+\mathrm{O}_{2}$ & (1) & $1.9 \times 10^{-11} e^{230 / T}$ \\
\hline 6. & $\mathrm{O}+\mathrm{O}_{3} \rightarrow 2 \mathrm{O}_{2}$ & (2) & $8.0 \times 10^{-12} e^{-2060 / T}$ \\
\hline 7. & $\mathrm{O}_{3}+\mathrm{OH} \rightarrow \mathrm{O}_{2}+\mathrm{HO}_{2}$ & (1) & $1.7 \times 10^{-12} e^{-940 / T}$ \\
\hline 8. & $\mathrm{O}_{3}+\mathrm{HO}_{2} \rightarrow \mathrm{OH}+2 \mathrm{O}_{2}$ & (1) & $1.0 \times 10^{-14} e^{-490 / T}$ \\
\hline 9. & $\mathrm{O}_{3}+\mathrm{Br} \rightarrow \mathrm{BrO}+\mathrm{O}_{2}$ & (1) & $1.7 \times 10^{-11} e^{-800 / T}$ \\
\hline
\end{tabular}

nine reactions as $\tau_{\mathrm{O}_{\mathrm{x}}}=\left[\mathrm{O}_{\mathrm{x}}\right] \Sigma \alpha_{i} L_{i}$, where $\left[\mathrm{O}_{\mathrm{x}}\right]=\left[\mathrm{O}_{3}+\mathrm{O}\right]$ is the photochemical model odd oxygen concentration, $\Sigma \alpha_{i} L_{i}$ represents the sum of the individual loss rates, and the factor $\alpha_{i}$ is the total number of odd oxygen atoms lost per reaction. For example, the first loss reaction in Table A1 removes one odd oxygen molecule per hydroxyl radical so that $\alpha_{1} L_{1}=k_{1}[\mathrm{OH}]$. Scaling $\tau_{\mathrm{O}_{\mathrm{x}}}$ by the ratio $\frac{\left[\mathrm{O}_{3}\right]}{\left[\mathrm{O}_{\mathrm{x}}\right]}$ using the ozone and odd oxygen concentrations from the CHEM2D model gives the ozone relaxation time $\tau_{\mathrm{O}_{3}}$, which is stored offline in a look-up table as a function of latitude, pressure, and time of year. The CHEM2D-OPP scheme in the NOGAPS-ALPHA model reads in the values of $\tau_{\mathrm{O}_{3}}$ and converts them to values of the linearized photochemistry coefficient $\frac{\partial(P-L)}{\partial r}=-\tau_{\mathrm{O}_{3}}^{-1}$.

Table A1 lists the temperature-dependent reaction rates for odd oxygen loss in the middle atmosphere. Evaluation of the temperature dependence can be performed analytically (Stolarski and Douglass, 1985) or numerically, as in the CHEM2D-OPP scheme. Numerical solutions for the temperature dependence are obtained by introducing a temperature perturbation $\Delta T$ in the reaction rates while holding the concentrations of the long-lived species (e.g., $\mathrm{O}_{2}, \mathrm{CH}_{4}, \mathrm{Cl}_{\mathrm{y}}$, $\mathrm{NO}_{\mathrm{y}}$ ) fixed, and then computing new corresponding values of $(P-L)_{\mathrm{O}_{\mathrm{x}}}$. As described in the text, the relation $\Delta(P-L)_{\mathrm{O}_{\mathrm{x}}}$ versus $\Delta T$ computed with the CHEM2D model (Fig. 3) produces estimates of the coefficient $\left.\frac{\partial(P-L)}{\partial T}\right|_{o}$ after scaling by $(1+\hat{p})^{-1}$.

The photolysis terms $J_{2}$ and $J_{3}$ both depend on the overhead integrated ozone column amount $\Sigma_{\mathrm{O}_{3}}(z)$. Ozone photolysis via $J_{3}$ is a sink for $\mathrm{O}_{3}$ but a source for $\mathrm{O}$, therefore it does not enter explicitly into the net odd oxygen tendency $(P-L)_{\mathrm{O}_{\mathrm{x}}}$ (see Eqs. A1 and 5) in the main text). To compute the sensitivity term $\left.\frac{\partial(P-L)}{\partial \Sigma_{\mathrm{O}_{3}}}\right|_{o}$, values of the overhead ozone column $\Sigma_{\mathrm{O}_{3}}$ used to calculate the CHEM2D photolysis frequency $J_{2}$ are perturbed by $\pm 50 \%$ while the concentrations of all other constituents are held fixed. Using this method, the column term expressed here is simply the sensitivity of the rate $J_{2}\left[\mathrm{O}_{2}\right]$ to changes in the overhead ozone column amount.

Figure A2a plots CHEM2D values of $J_{2}$ and $J_{3}$ for March conditions at $30^{\circ} \mathrm{N}$; the reduction in $J_{2}$ for an imposed $10 \%$ increase in $\Sigma_{\mathrm{O}_{3}}$ is plotted in Fig. A2b. Since an increase in $\Sigma_{\mathrm{O}_{3}}$ decreases $J_{2}$ in (A1), the sign of the column term $\left.\frac{\partial(P-L)}{\partial \Sigma_{\mathrm{O}_{3}}}\right|_{o}$ is negative throughout the stratosphere (see Fig. 6). An increase in $\Sigma_{\mathrm{O}_{3}}$ also reduces $J_{3}$, meaning less ozone is lost through photolysis. However, this has a zero net effect on the odd oxygen tendency since ozone photolysis is a source of atomic oxygen as well as a sink of ozone. This differs from the photolysis perturbation term $C$ derived from the linearized set of Chapman (i.e., oxygen-only) photochemical reactions in earlier studies (e.g., Hartmann, 1978), where it is assumed that $[\mathrm{O}]$ remains in photochemical equilibrium in the upper stratosphere (i.e., above $10 \mathrm{hPa}$ ) where ozone photochemistry is fast. Under this assumption the ozone concentration can be expressed as

$\left[\mathrm{O}_{3}\right]_{e q}=\left(\frac{J_{2} k_{1}\left[\mathrm{O}_{2}\right]^{2}[\mathrm{M}]}{J_{3} k_{3}}\right)^{\frac{1}{2}}$.

This relationship does not hold for generalized ozone photochemistry (see, e.g., Brasseur and Solomon (1986), their equations 5.251-5.253). Because of the increased complexity of the generalized ozone balance when reactions with $\mathrm{HO}_{\mathrm{x}}, \mathrm{NO}_{\mathrm{x}}, \mathrm{ClO}_{\mathrm{x}}$, and $\mathrm{BrO}_{\mathrm{x}}$ are included, a more tractable approach for determining the column sensitivity term is to estimate $\left.\frac{\partial(P-L)}{\partial \Sigma_{\mathrm{O}_{3}}}\right|_{o}$ numerically by computing the change in the model odd oxygen tendency $\Delta(P-L)_{\mathrm{O}_{\mathrm{x}}}$ in response to imposed changes in column ozone $\Delta \Sigma_{\mathrm{O}_{3}}$ while holding other variables, (i.e., $\left[\mathrm{O}_{\mathrm{x}}\right], T$, other constituents, transport) fixed, as illustrated in Fig. 4.

Acknowledgements. We gratefully acknowledge D. Cariolle and H. Teyssedre of Meteo-France for providing the CD86 photochemistry coefficients, I. S̆tajner of NASA GMAO for providing the GSFC photochemistry rates, and the Aura MLS science team. Special thanks to T. Hogan of NRL-Monterey for assistance in developing NOGAPS-ALPHA and providing initial conditions, and to A. Geer of the University of Reading (UK) for helpful discussions. We also wish to thank two anonymous referees for their constructive comments. This work was supported by a grant from the NOAA/NASA/DoD Joint Center for Satellite Data Assimilation and by the Office of Naval Research. NOGAPS-ALPHA simulations were made possible by a grant of computer time from the DoD High Performance Computing Modernization Program at the U.S. Army Engineer Research and Development Center and at the U.S. Army Space and Missile Defense Command Simulation Center.

Edited by: V. Fomichev 


\section{References}

Austin, J., Shindell, D., Beagley, S. R., et al.: Uncertainties and assessments of chemistry-climate models of the stratosphere, Atmos. Chem. Phys., 3, 1-27, 2003,

http://www.atmos-chem-phys.net/3/1/2003/.

Bacmeister, J. T., Siskind, D. E., Summers, M. E., and Eckermann, S. D.: Age of air in a zonally averaged two-dimensional model, J. Geophys., Res., 103, 11 263-11 288, 1998.

Barnett, J. J., Houghton, J. T., and Pyle, J. A.: The temperature dependence of ozone at the stratopause, Quart. J. Roy. Meteorol. Soc., 101, 245-257, 1975.

Blake, D. and Lindzen, R. S.: Effect of photochemical models on calculated equilibria and cooling rates in the stratosphere, Mon. Wea. Rev., 101, 783-802, 1973.

Bloom, S., da Silva, A., Dee, D., Bosilovich, M., Chern, J.-D., Pawson, S., Schubert, S., Sienkiewicz, M., S̆tajner, I., Tan, W.W., and $\mathrm{Wu}, \mathrm{M}$.-L.: Documentation and validation of the Goddard Earth Observing System (GEOS) data assimilation system - version 4, NASA Tech. Mem. NASA/TM-2005-104606, 15, Technical Report Series on Global Modeling and Data Assimilation, edited by: Suarez, M. J., 165pp., available online at http://ntrs.nasa.gov, 2005.

Brasseur, G., and S. Solomon, 1986: Aeronomy of the Middle Atmosphere, 2nd ed., 452pp, D. Reidel, Norwell MA, USA.

Burris, J., McGee, T., Hoegy, W., et al.: Validation of temperature measurements from the airborne Raman ozone temperature and aerosol lidar during SOLVE, J. Geophys. Res., 107(D20), 8286, doi:10.1029/2001JD001028, 2002.

Cariolle, D. and Dèqué, M.: Southern hemisphere medium-scale waves and total ozone disturbances in a spectral general circulation model, J. Geophys. Res., 91, 10 825-10 846, 1986.

Chou, M.-D., Suarez, M. J., Liang, X. Z., and Yan, M.-H.: A thermal infrared radiation parameterization for atmospheric studies, NASA Tech. Mem. 104606, 19, Technical Report Series on Global Modeling and Data Assimilation, edited by: Suarez, M. J., 65pp., 2001.

Chou, M.-D. and Suarez, M. J.: A solar radiation parameterization for atmospheric studies, NASA Tech. Mem. 10460, 15, Technical Report Series on Global Modeling and Data Assimilation, edited by: Suarez, M. J., 52pp., 2002.

Daley, R. and Barker, E.: NAVDAS: formulation and diagnostics, Mon. Wea. Rev., 129, 869-883, 2001.

Derber, J. C. and Wu, W.-S.: The use of TOVS cloud-cleared radiances in the NCEP SSI analysis system, Mon. Wea. Rev., 126, 2287-2299, 1998.

Dethof, A. and Holm, E. V.: Ozone assimilation in the ERA-40 reanalysis project, Q. J. R. Meteorol. Soc., 130, 2851-2872, 2004.

Douglass, A. R., Rood, R. B., and Stolarski, R. S.: Interpretation of ozone temperature correlations, 2, Analysis of SBUV ozone data, J. Geophys. Res., 90, 10 693-10 708, 1985.

Douglass, A. R. and Rood, R. B.: Derivation of photochemical information near 1 mbar from ozone and temperature data, J. Geophys. Res., 91, 11,153-11,156, 1986.

Eckermann, S. D., McCormack, J. P., Coy, L., Allen, D., Hogan, T., and Kim, Y.-J.: NOGAPS-ALPHA: A prototype high-altitude global NWP model, Paper P2.6, Preprint Volume, Symposium on the 50th Anniversary of Operational Numerical Weather Prediction, Am. Meteorol. Soc., University of Maryland, College Park, MD, 14-17 June, 23pp., 2004.
Eckermann, S. D., Wu, D., Doyle, J. D., Coy, L., Lawrence, B. N., Stephens, A., McCormack, J. P., and Hogan, T. F.: Imaging gravity waves in lower stratospheric AMSU-A radiances, Part 2: Validation case study, Atmos. Chem. Phys., 6, 3343-3362, 2006, http://www.atmos-chem-phys.net/6/3343/2006/.

Eckermann, S. D. and McCormack, J. P.: Climatological ozone mixing ratios in NOGAPS-ALPHA, NRL Draft Technical Report, 17pp., 2006.

Fleming, E. L., Chandra, S., Barnett, J. J., and Corney, M.: Zonal mean temperature, pressure, zonal wind, and geopotential height as functions of latitude, COSPAR International Reference Atmosphere: 1986, Part II: Middle Atmosphere Models, Adv. Space Res., 10(12), 11-59, 1990.

Fleming E. L., Jackman, C. H., Rosenfield, J. E., and Considine, D. B.: Two-dimensional model simulations of the QBO in ozone and tracers in the tropical stratosphere, J. Geophys. Res., 107(D23), 4665, doi:10.1029/2001JD001146, 2002.

Fomichev, V. I., Blanchet, J. P., and Turner, D. S.: Matrix parameterization of the $15 \mu \mathrm{m}$ band $\mathrm{CO}_{2}$ cooling in the middle and upper atmosphere for variable $\mathrm{CO}_{2}$ concentration, J. Geophys. Res., 103, 11 505-11 528, 1998.

Fortuin, J. P. F. and Kelder, H.: An ozone climatology based on ozonesonde and satellite measurements, J. Geophys. Res., 103, 31 709-31 734, 1998.

Froidevaux, L., Allen, M., Berman, S., and Daughton, A.: The mean ozone profile and its temperature sensitivity in the upper stratosphere and mesosphere: an analysis of LIMS observations, J. Geophys. Res., 94, 6389-6417, 1989.

Froideveaux, L., Livesey, N. J., Read, W. G., et al.: Early validation analyses of atmospheric profiles from EOS MLS on the Aura satellite, IEEE Trans. Geosci. Remote Sensing, 44, 1106-1121, 2006.

Geer, A. J., Peubey, C., Banister, R., Brugge, R., Jackson, D. R., Lahoz, W. A., Migliorini, S., O’Neill, A., and Swinbank, R.: Assimilation of stratospheric ozone from MIPAS into a global general circulation model: the September 2002 vortex split, Q. J. R. Meteorol. Soc., 132, 231-257, 2006a.

Geer, A. J., Lahoz, W. A., Jackson, D. R., Cariolle, D., and McCormack, J. P.: Evaluation of linear ozone photochemistry parameterizations in a stratosphere-troposphere data assimilation system, Atmos. Chem. Phys. Discuss., 6, 7427-7469, 2006b.

Goerrs, J. and Phoebus, P.: The Navy's operational atmospheric analysis, Mon. Wea. Forecasting, 7, 232-249, 1992.

Hadjinicolaou, P. and Pyle, J. A.: The impact of Arctic ozone depletion on northern middle latitudes: Interannual variability and dynamical control, J. Atm. Chem., 47, 25-43, 2004.

Harries, J. F., Russell, J. M., Tuck, A. F., et al: Validation of measurements of water vapor from the Halogen Occultation Experiment (HALOE), J. Geophys. Res., 101, 10 202-10 216, 1996.

Hartmann, D. L.: A note concerning the effect of varying extinction on radiative-photochemical equilibrium, J. Atmos. Sci., 35, 1125-1130, 1978.

Hartmann, D. L. and Garcia, R. R.: A mechanistic model of ozone transport by planetary waves in the stratosphere, J. Atmos. Sci., 36, 350-364, 1979.

Hogan, T. and Rosmond, T.: The description of the Navy Operational Global Atmospheric Prediction System's spectral forecast model, Mon. Wea. Rev., 119, 1186-1815, 1991.

Jackson, D. and Saunders, R.: Ozone data assimilation system: Pre- 
liminary system, United Kingdom Meteorological Office Forecasting Research Technical Report No. 394, 18pp., 2002.

John, V. O. and Buehler, S. A.: The impact of ozone lines on AMSU-B radiances, Geophys. Res. Lett., 31, L21108, doi:10.1029/2004GL021214, 2004.

Kistler, R., Kalnay, E., Collins, W., et al.: The NCEP-NCAR 50Year Reanalysis: Monthly Means CD-ROM and Documentation, Bull. Am. Meteorol. Soc., 82(2), 247-267, 2001.

Lindzen, R. S. and Goody, R.: Radiative and photochemical processes in mesospheric dynamics: Part I, models for radiative and photochemical processes, J. Atmos. Sci., 22, 341-348, 1965.

Long, C. S.: UV index forecasting practices around the world, SPARC Newsletter, No. 21, 20-23, 2003.

McCormack, J. P. and Siskind, D. E.: Simulations of the quasibiennial oscillation and its effect on stratospheric $\mathrm{H}_{2} \mathrm{O}, \mathrm{CH}_{4}$, and age of air with an interactive two-dimensional model, J. Geophys. Res., 107, 4625, doi:10.1029/2002JD002141, 2002.

McCormack, J. P., Eckermann, S. D., Coy, L., et al.: NOGAPSALPHA model simulations of stratospheric ozone during the SOLVE2 campaign, Atmos. Chem. Phys., 4, 2401-2423, 2004, http://www.atmos-chem-phys.net/4/2401/2004/.

McLinden, C. A., Olsen, S. C., Hannegan, B., Wild, O., Prather, M. J., and Sundet, J.: Stratospheric ozone in 3-D models: A simple chemistry and the cross-tropopause flux, J. Geophys. Res., 105, $14653-14665,2000$.

NCEP Office Note 442: The GFS Atmospheric Model, Environmental Modeling Center, National Centers for Atmospheric Prediction, Washington, DC, http://www.emc.ncep.noaa.gov/ officenotes/newernotes/on442.pdf, 2003.

Peuch, A., Thépaut, J.-N., and Pailluex, J.: Dynamical impact of total-ozone observations in a four-dimensional variational assimilation, Q. J. R. Meteorol. Soc., 126, 1641-1659, 2000.

Randel, W. J.: Kelvin wave-induced trace constituent oscillations in the equatorial stratosphere, J. Geophys. Res., 95, 18 641-18 652, 1990.

Randel, W. J.: Global variations of zonal mean ozone during stratospheric warming events, J. Atmos. Sci., 50, 3308-3321, 1993.

Randel, W. J. and Gille, J. C.: Kelvin wave variability in the upper stratosphere observed in SBUV data, J. Atmos. Sci., 48, 23362349, 1991.

Randel, W., Udelhofen, P., Fleming, E., et al.: The SPARC intercomparison of middle-atmosphere climatologies, J. Clim., 17, 986-1003, 2004.

Riishøgaard, L. P., Stajner, I., and Lou, G.-P.: The GEOS ozone data assimilation system, Adv. Space Res., 25, 1063-1072, 2000.

Salby, M. L., Callaghan, P., Solomon, S., and Garcia, R. R.: Chemical fluctuations associated with vertically propagating equatorial Kelvin waves, J. Geophys. Res., 95, 20 491-20 505, 1990.

Sander, S. P., Friedl, R. R., Ravishankara, A. R., et al.: Chemical kinetics and photochemical data for use in atmospheric studies, Evaluation No. 14, Jet Propulsion Laboratory, Pasadena CA, USA, 2003.
Sassi, F., Boville, B. A., Kinnison, D., and Garcia, R. R.: The effects of interactive ozone photochemistry on simulations of the middle atmosphere, Geophys. Res. Lett., 32, L07811, doi:10.1029/2004GL022131, 2005.

Siskind, D. E.: On the coupling between middle and upper atmospheric odd nitrogen, Atmospheric Science Across the Stratopause, Geophysical Monograph Series no. 123, edited by: Siskind, D. E., Eckermann, S. D., and Summers, M. E., Am. Geophys. Union, 342pp., 2000.

Siskind, D. E., Eckermann, S. D., McCormack, J. P., et al.: Hemispheric differences in the temperature of the summertime stratosphere and mesosphere, J. Geophys. Res., 108(D2), 4051, doi:10.1029/2002JD002095, 2003.

Smith, A. K.: Numerical simulation of global variations of temperature, ozone, and trace species in the stratosphere, J. Geophys. Res., 100, 1253-1269, 1995.

Stajner, I., Riishøjgaard, L. P., and Rood, R. B.: The GEOS ozone data assimilation system: Specification of error statistics, Q. J. R. Meteorol. Soc., 127, 1069-1094, 2001.

S̆tajner, I., Winslow, N., Rood, R. B., and Pawson, S.: Monitoring of observation errors in the assimilation of satellite ozone data, J. Geophys. Res., 109, D06309, doi:10.1029/2003JD004118, 2004.

Stolarski, R. S. and Douglass, A. R.: Parameterization of the photochemistry of stratospheric ozone including catalytic loss processes, J. Geophys. Res., 90, 10 709-10 718, 1985.

Strobel, D. F.: Photochemical-radiative damping and instability in the stratosphere, Geophys. Res. Lett., 4, 424-426, 1977.

Summers, M. E., Siskind, D. E., Bacmeister, J. T., Conway, R. R., Zasadil, S. E., and Strobel, D. F.: Seasonal variation of middle atmospheric $\mathrm{CH}_{4}$ and $\mathrm{H}_{2} \mathrm{O}$ with a new chemical-dynamical model, J. Geophys. Res., 102, 3503-3526, 1997.

Swinbank, R. and Ortland, D. A.: Compilation of wind data for the Upper Atmosphere Research Satellite (UARS) Reference Atmosphere Project, J. Geophys. Res., 108, D19, 4615, doi:10.1029/2002JD003135, 2003.

Turco, R. P. and Whitten, R. C.: A note on the diurnal averaging of aeronomical models, J. Atmos. Terr. Phys., 40, 13-20, 1978.

Untch, A., Simmons, A. J., Hortal, M., and Jakob, C.: Increased stratospheric resolution in the ECMWF forecasting system, Proceedings of the SODA Workshop, 9-10 December 1998, KNMI, de Bilt, then Netherlands, 45-52, 1999.

Wang, H. J., Cunnold, D. M., Froideveaux, L., and Russell, J. M.: A reference model for middle atmosphere ozone in 1992-1993, J. Geophys. Res., 104, 21 629-21 643, 1999.

Zhu, X., Summers, M. E., and Strobel, D. F.: Calculation of $\mathrm{CO}_{2} 15$ micron band atmospheric cooling rates by Curtis matrix interpolation of correlated k-coefficients, J. Geophys. Res., 97, 12787 $12797,1992$. 